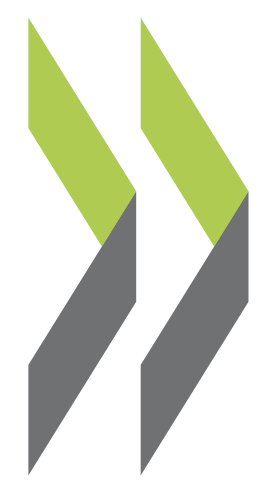

OECD Science, Technology and Industry Working Papers 2006/09

\title{
The Changing Nature of Manufacturing in OECD Economies
}

\section{Dirk Pilat,}

Agnès Cimper, Karsten Bjerring Olsen, Colin Webb 
Organisation de Coopération et de Développement Economiques

Organisation for Economic Co-operation and Development

27-Oct-2006

DIRECTORATE FOR SCIENCE, TECHNOLOGY AND INDUSTRY

English - Or. English

THE CHANGING NATURE OF MANUFACTURING IN OECD ECONOMIES

STI WORKING PAPER 2006/9

Dirk Pilat, Agnès Cimper, Karsten Olsen and Colin Webb 


\section{STI Working Paper Series}

The Working Paper series of the OECD Directorate for Science, Technology and Industry is designed to make available to a wider readership selected studies prepared by staff in the Directorate or by outside consultants working on OECD projects. The papers included in the series cover a broad range of issues, of both a technical and policy-analytical nature, in the areas of work of the DSTI. The Working Papers are generally available only in their original language - English or French - with a summary in the other.

Comments on the papers are invited, and should be sent to the Directorate for Science, Technology and Industry, OECD, 2 rue André-Pascal, 75775 Paris Cedex 16, France.

The opinions expressed in these papers are the sole responsibility of the author(s) and do not necessarily reflect those of the OECD or of the governments of its member countries.

\section{http://www.oecd.org/sti/working-papers}




\begin{abstract}
This paper provides empirical evidence on the changing nature of manufacturing in OECD countries, including the continued loss of employment in the manufacturing. It examines the extent to which manufacturing output and employment are declining in OECD countries and explores possible causes, including increased productivity, slow growth in demand for manufacturing products, loss of markets to imports, statistical and classification issues, and so on. The paper finds that the share of manufacturing in OECD economies is declining and argues that this is likely to continue. It also presents evidence pointing to an increased blurring of the distinction between manufacturing and services. Furthermore, it notes that manufacturing is becoming more and more integrated at the global level. Finally, it noted that although manufacturing production is declining in OECD countries, innovation in this sector continues to be dominated by OECD countries. The paper is a contribution to an OECD project on global value chains, and will also contribute to OECD work on globalisation and structural change.
\end{abstract}

N.B. This paper also exists in French. 


\section{TABLE OF CONTENTS}

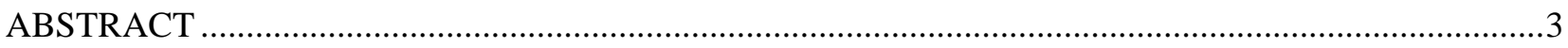

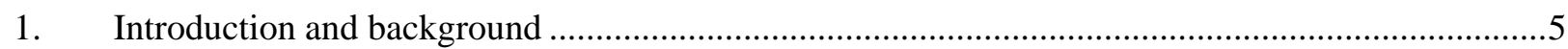

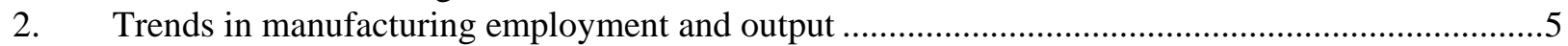

Manufacturing employment has declined steadily in most OECD countries..........................................5

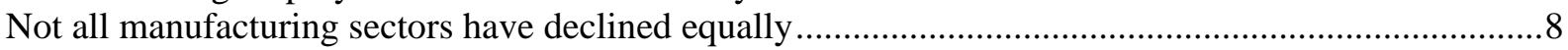

High-technology manufacturing is also being affected by employment losses .....................................

Manufacturing employment in non-OECD countries has not grown..................................................10

Manufacturing production and value added have continued to experience strong growth .....................10

Demand for manufacturing goods remains high ...................................................................................13

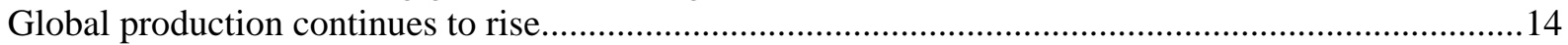

3. Trends in the internationalisation of manufacturing ...................................................................16

Manufacturing trade is increasing more rapidly than global production................................................16

Inter-industry trade is important, pointing to the integration of value chains .....................................17

There are winners and losers in the global market place........................................................................18

The comparative advantage of OECD countries differs considerably ................................................19

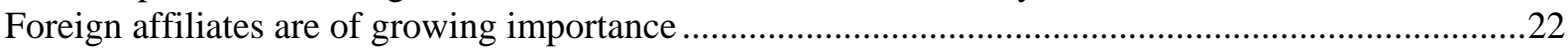

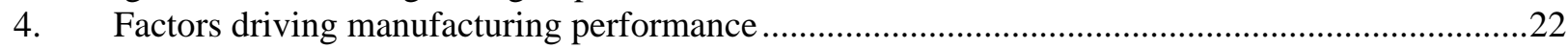

Productivity growth in manufacturing remains high in many OECD countries ................................22

Gaps in productivity levels across countries are large and persistent .............................................24

Labour costs differ enormously across countries, but also reflect productivity gaps.............................25

The manufacturing sector still accounts for the bulk of spending on research and development..........26

OECD countries continue to dominate global innovation.....................................................................28

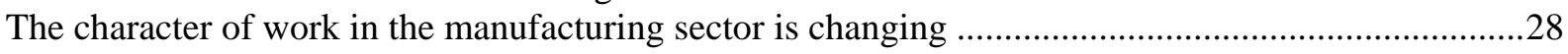

The distinction between services and manufacturing is blurring ..........................................................31

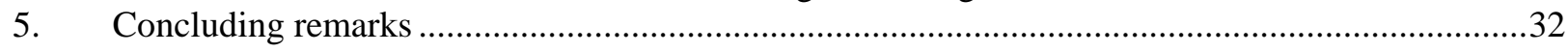

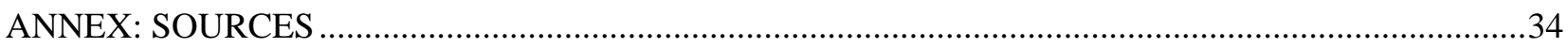

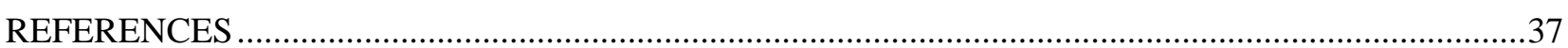


DSTI/DOC(2006)9

\section{THE CHANGING NATURE OF MANUFACTURING IN OECD ECONOMIES}

\section{Introduction and background}

De-industrialisation of OECD economies is back on the policy agenda in many OECD countries. Recent policy studies in several OECD countries, including the United States, the United Kingdom, Belgium and the Netherlands, point to the ongoing loss of manufacturing employment in OECD economies and raise questions about the future of manufacturing in OECD economies (US Department of Commerce, 2004; Department of Trade and Industry, 2004; Bureau Fédéral du Plan, 2004; Ministry of Economic Affairs, 2004). Questions that are raised include: Will the current decline of manufacturing employment continue in OECD economies? Is off-shoring of manufacturing production a threat or an opportunity for OECD economies? To what extent is the loss of manufacturing threatening future innovation and technological progress in OECD economies? Can future prosperity in OECD economies be ensured without a vibrant manufacturing sector (Conference Board, 2004a)? These questions, and others, are raised against the background of a growing role of certain non-OECD economies, notably China, in global manufacturing.

This paper provides empirical evidence to help develop a response to these questions. It examines the extent to which manufacturing output and employment are declining in OECD countries and explores possible causes, including increased productivity, slow growth in demand for manufacturing products, loss of markets to imports, statistical and classification issues, and so on. The paper also provides empirical material to help increase understanding of the evolving global business models of manufacturing enterprises, especially multinational enterprises (MNES), which feature global supply chains comprised of many smaller services and manufacturing companies. The paper is a contribution to an OECD project on global value chains, and also contributes to OECD work on globalisation and structural change. It will be complemented with other studies, including work examining input-output relationships between countries and work with firm level data.

The paper includes four substantive sections; section 2 examines trends in employment and output; section 3 looks at trends in the internationalisation of manufacturing; while section 4 examines trends in the key drivers of manufacturing performance. Section 5 concludes and briefly discusses some issues that will require further examination in developing policies that may help address these trends.

\section{Trends in manufacturing employment and output}

\section{Manufacturing employment has declined steadily in most OECD countries}

Economic development in OECD economies has long been characterised by a gradual process of structural change. In the initial stages of economic development, agriculture typically accounts for the bulk of GDP and employment, as is still the case in many developing countries. In later stages, its share in total value added and employment declines and the manufacturing sector grows as economies industrialise. In recent years, many OECD economies have experienced a decline in the share of manufacturing in overall employment, with a concurrent rise in the share of services (Figure 1). 


\section{DSTI/DOC(2006)9}

Figure 1. Share of main activities in employment, selected OECD economies, 1700-2002, in \% $\square$ Agriculture $\square$ Industry $\square$ Services

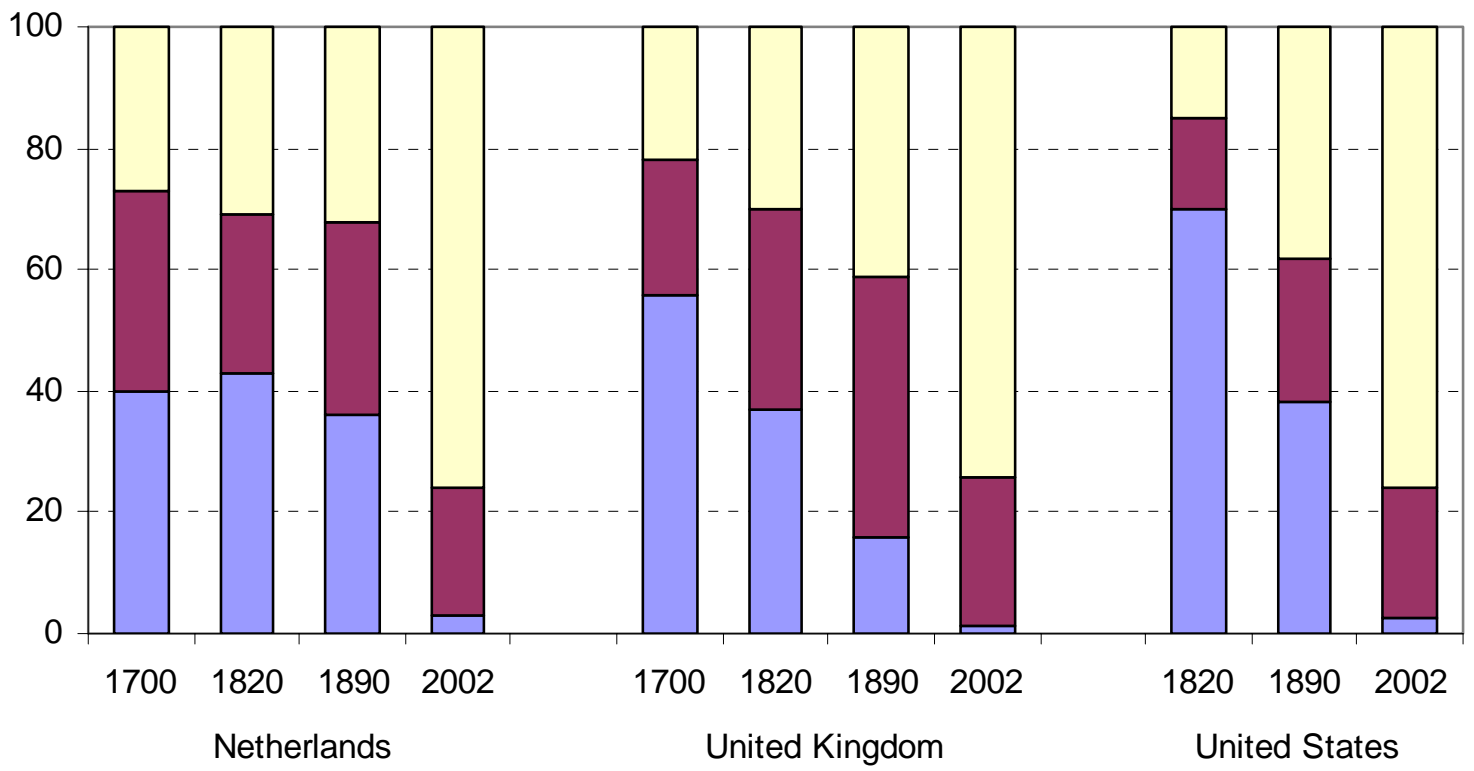

Source: Maddison (2001) and OECD Labour Force Statistics.

Much of the recent debate about de-industrialisation and the potential decline of the manufacturing base has focused on the loss of manufacturing employment in OECD countries. Cross-country evidence on manufacturing employment shows that most OECD countries have indeed experienced a steady decline in the share of manufacturing in total employment (Figure 2).

Figure 2. Share of manufacturing in total employment, G7 countries, $1970-2003$, in $\%$

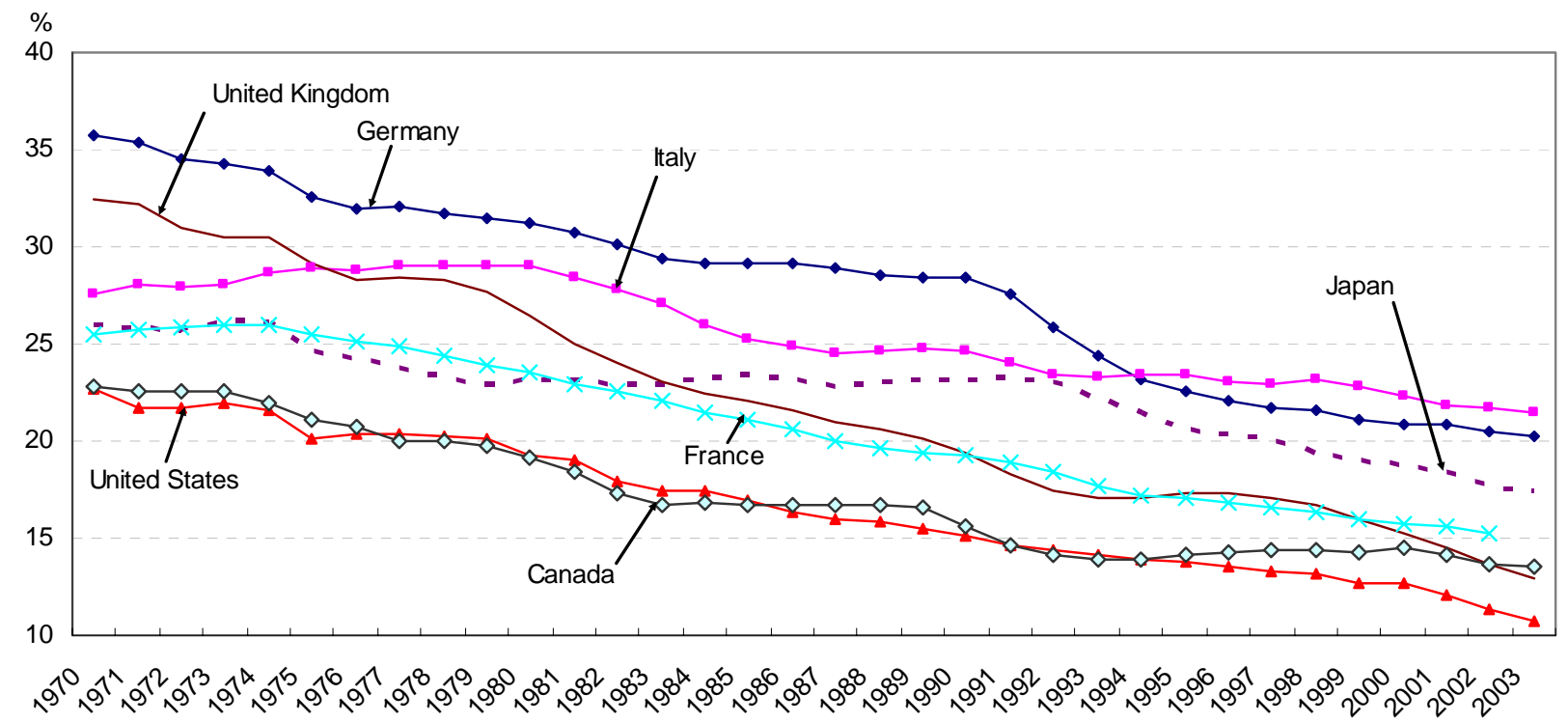

Source: OECD, STAN Indicators database, December 2005.

This pattern is broadly confirmed for other OECD countries (Figure 3). In most, the share of manufacturing has declined substantially since the 1970s, with Germany, the United Kingdom and 
Luxembourg showing the largest drop in employment shares from 1985 to 2002. In Canada, Ireland, Italy and Spain, the absolute share of manufacturing has declined the least over the past two decades. Underlying the declining share are two factors; an absolute decline in the number of manufacturing workers in virtually all OECD countries, with the exceptions of Canada, Ireland, Mexico, New Zealand and Spain (Figure 4), as well as rapid employment growth in the services sector (Wölfl, 2005).

Figure 3. Share of manufacturing in total employment, 1970, 1985 and $2003^{*}$

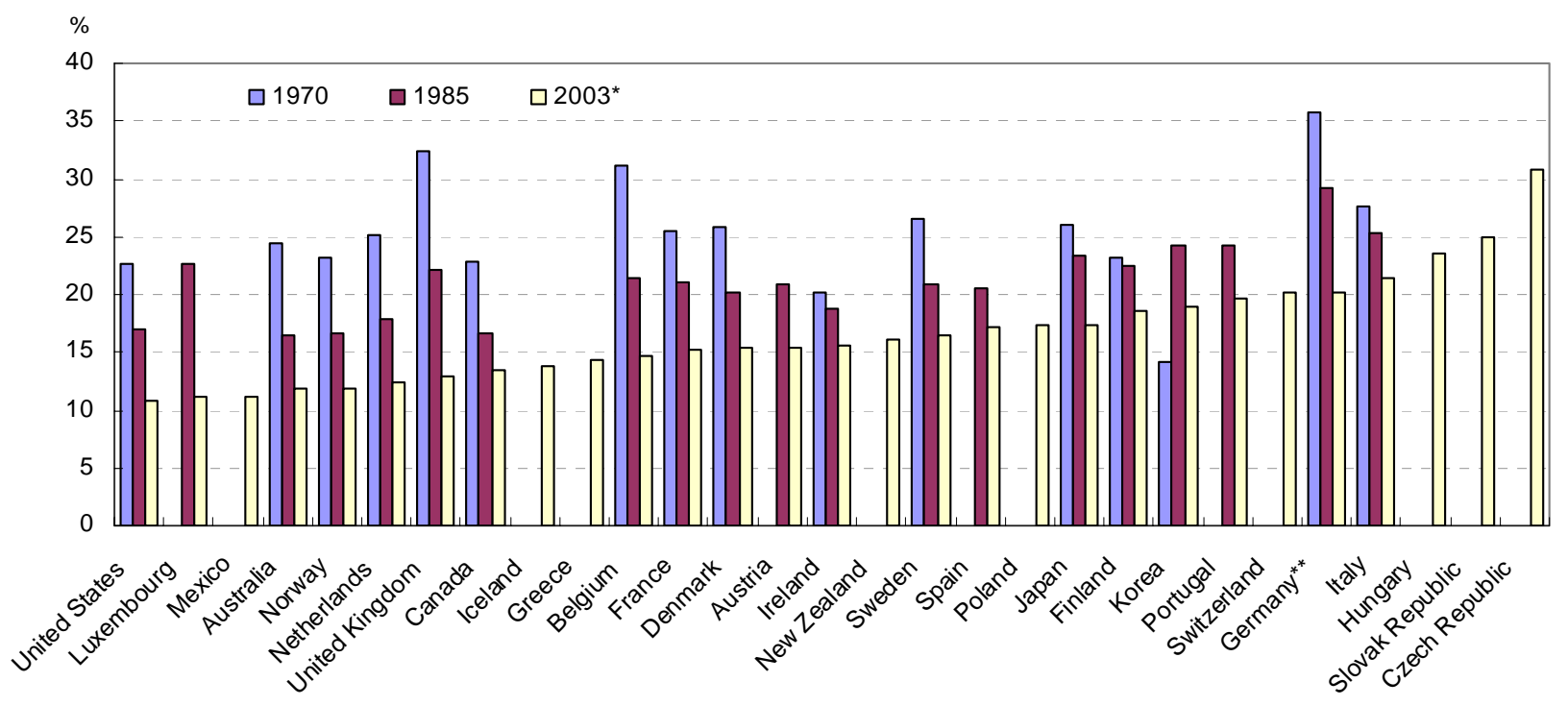

Note: *) Or latest available year. **) Germany before 1991 refers to West Germany.

Source: OECD, STAN Indicators database, December 2005.

Figure 4. Percentage change in manufacturing employment, 1990-2003*

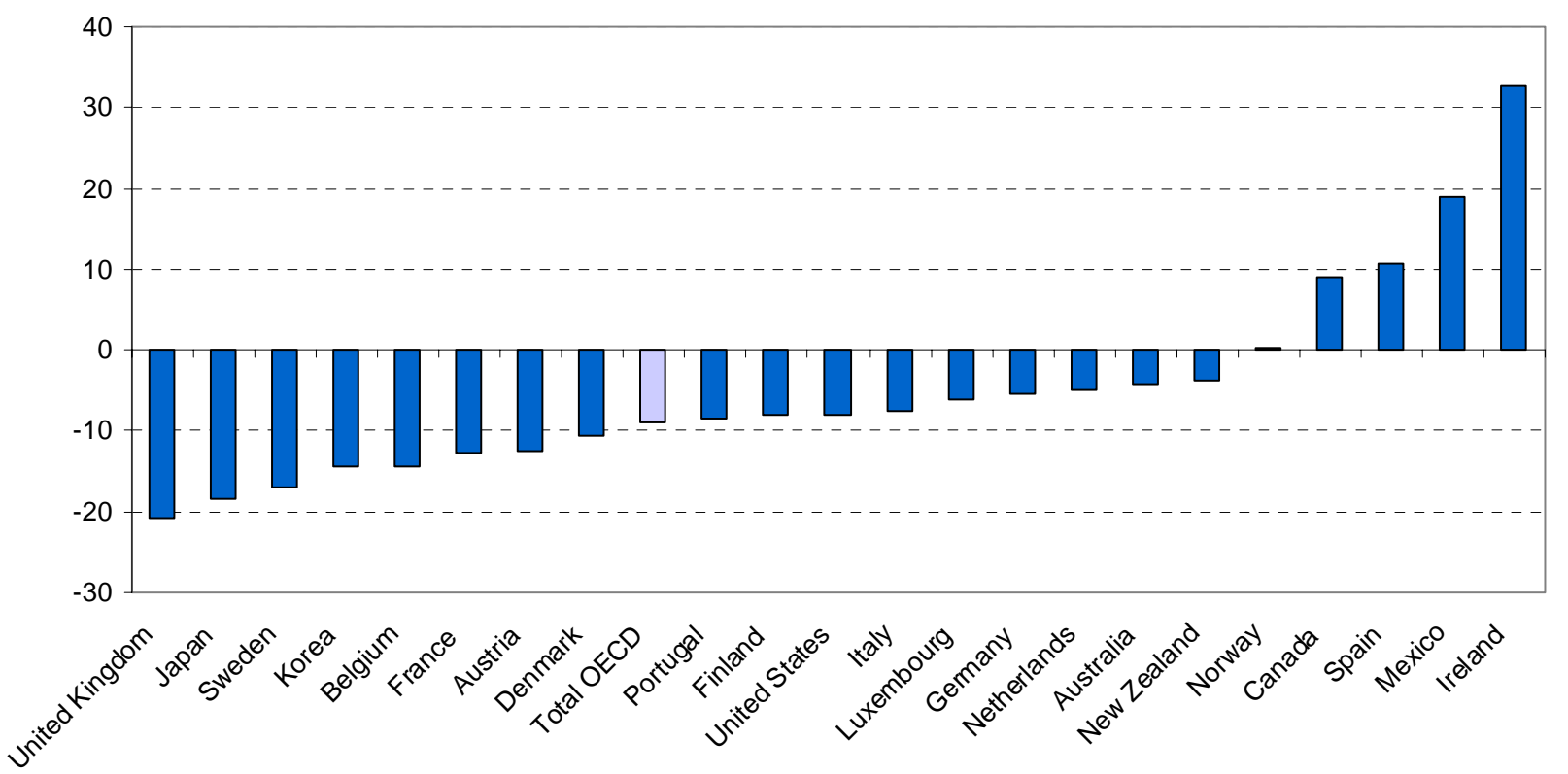

Note: *) Or latest available year. Germany before 1991 refers to West Germany. Data for Mexico refer to employees.

Source: OECD, STAN Indicators database, December 2005. 


\section{Not all manufacturing sectors have declined equally}

While overall manufacturing employment has declined, not all sectors have fared equally. Figure 5 shows manufacturing employment for key manufacturing sectors for the G7 countries, countries that account for approximately $70 \%$ of manufacturing employment in OECD countries. The graph shows that most of the decline in manufacturing employment over the past three decades has occurred in only two activities, textiles products and metal products. In several activities, notably food products, paper products, chemicals, motor vehicles and other manufacturing, manufacturing employment in the G7 countries has been relatively stable. In some others, such as wood products and machinery, it has only declined a little.

Figure 5. Manufacturing employment by key activity, G7 countries, 1970-2001, million workers

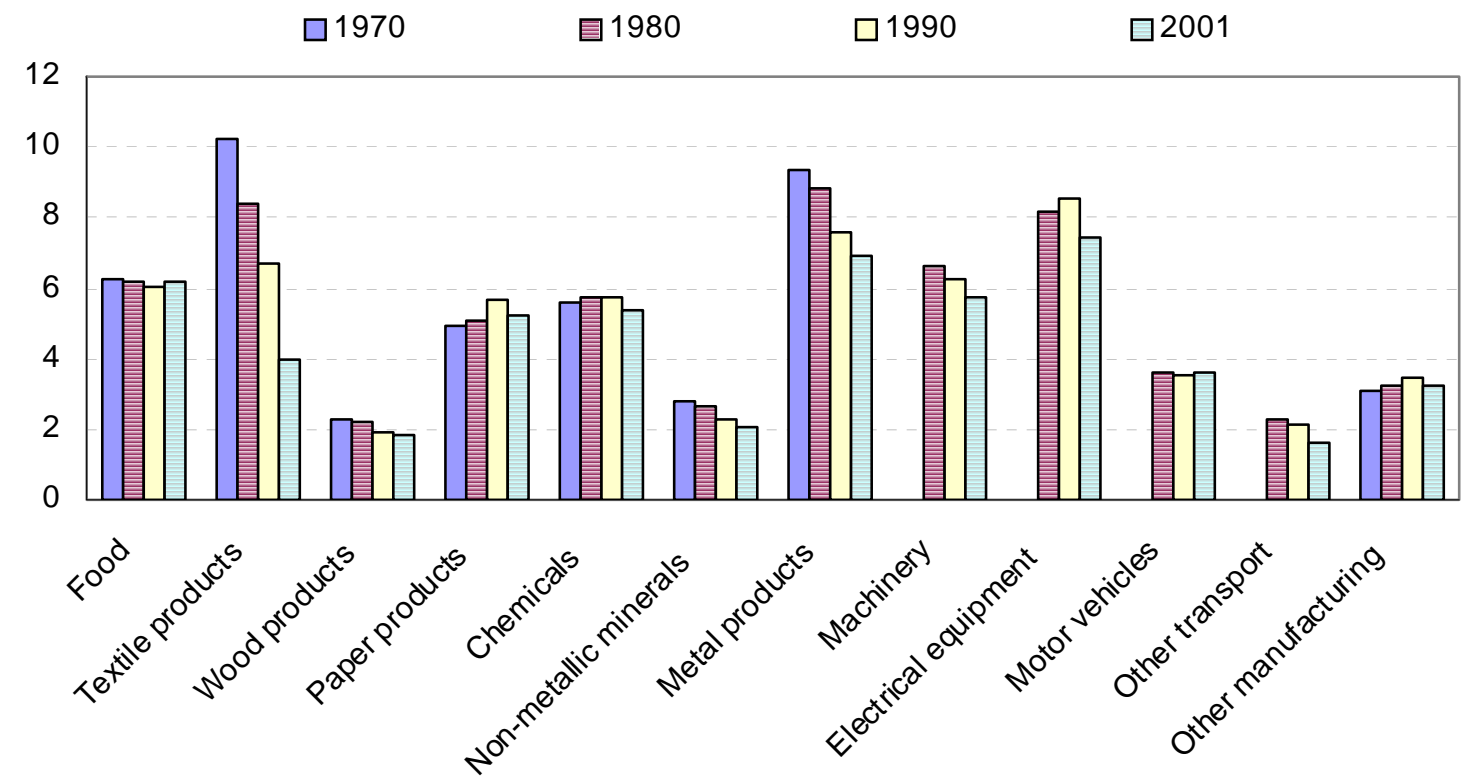

Source: OECD, STAN database, December 2005.

There are several reasons why there is such large variation in the experience of different manufacturing activities. First, OECD countries maintain a comparative advantage in certain sectors of manufacturing activity and have been faced with strong demand for products of certain manufacturing sectors, e.g. pharmaceuticals and motor vehicles. This has helped to maintain employment in these sectors; in certain OECD countries, employment in these industries has grown. Second, in certain industries, such as food products, manufacturing production is often located close to the market, and international competition is typically not an important source of job loss. Indeed, some industry analysts suggest that off-shoring of production in such industries may make little sense, since the benefits of having a short, responsive local supply chain may outweigh the costs of higher wages (Ritter and Sternfels, 2004). In other industries, notably textiles, international competition of low-cost countries has played an important role in reducing manufacturing employment in OECD countries and will likely become even more important with the recent change in the trade regime for this sector (OECD, 2004).

At the same time, there is considerable variation across OECD countries in the development of employment in key manufacturing industries. For example, while overall OECD employment in the computer industry in OECD countries has declined substantially over the past decade, Ireland, Mexico and Korea experienced an increase over the 1990s. In radio, TV and communications equipment, employment grew substantially during the 1990s in Ireland, Mexico, Finland and Sweden, while it declined in most other OECD countries. Similar patterns of specialisation are apparent in other industries; for example, 
while employment in shipbuilding declined in virtually all OECD countries over the 1990s, it increased in Korea and Norway. Some OECD countries thus continue to have a strong comparative advantage in manufacturing industries that may be considered susceptible to off-shoring.

\section{High-technology manufacturing is also being affected by employment losses}

The recent changes in OECD manufacturing employment do not reflect a shift from low- to hightechnology industries, as was the case in the 1980s (Figure 6). While OECD production and trade patterns in manufacturing clearly demonstrate the growing importance of high-technology manufacturing, employment data show that only one high-technology industry, pharmaceuticals, has experienced employment growth over the past decade (Figure 6). Other high-technology industries have all experienced a considerable decline, with computers and aircraft and spacecraft having the most rapid declines in employment of all manufacturing industries, with the exception of textile products.

Figure 6. Growth of OECD* manufacturing employment by technology intensity Average annual growth rates, in \%

1990-2003**
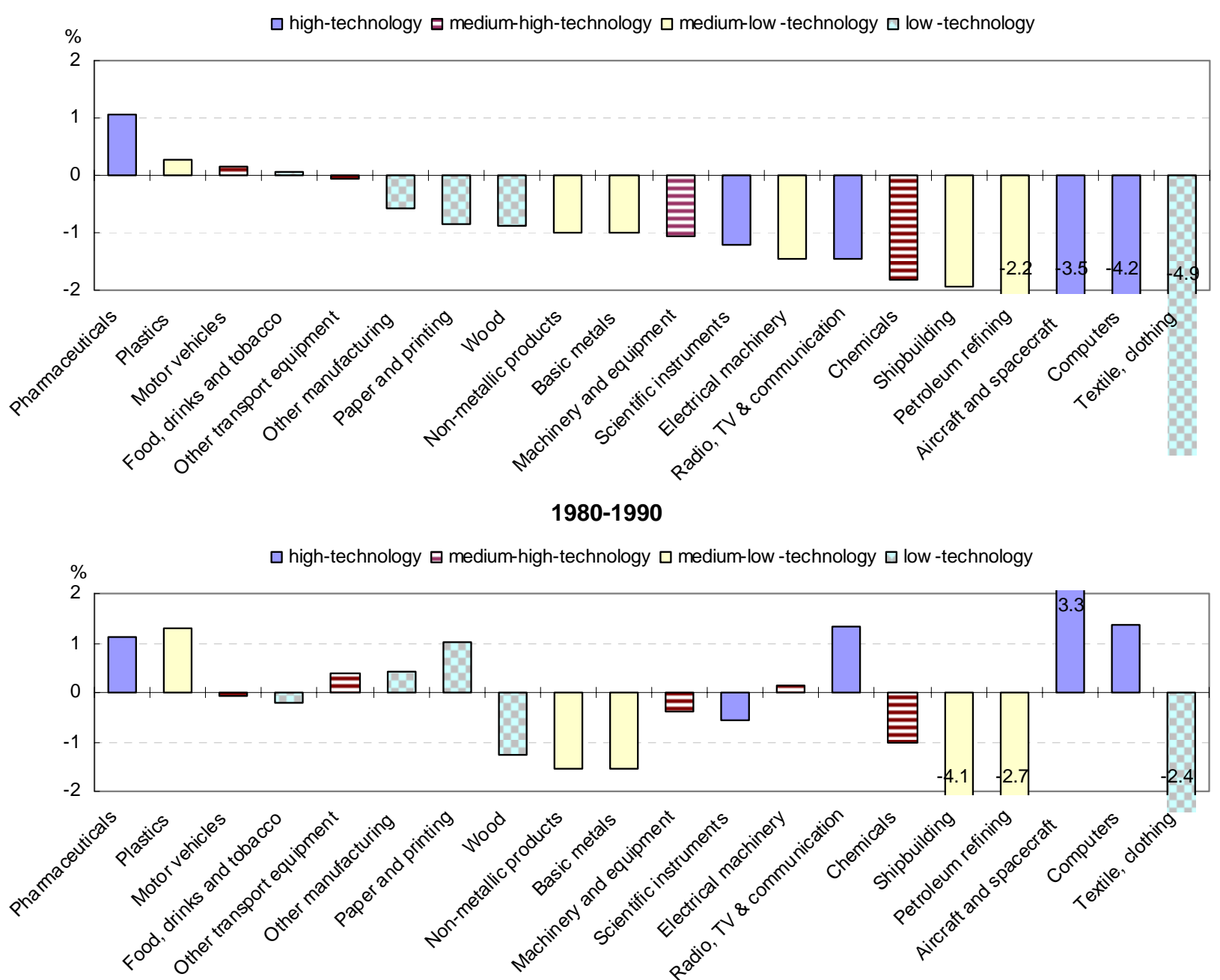

Note: *) OECD aggregate includes Austria, Canada, Denmark, Finland, France, Germany, Italy, Japan, Norway, Spain, Sweden, United Kingdom and United States. Data for United Kingdom refer to number of employees. ${ }^{\star *}$ ) Or latest available year.

Source: OECD, STAN Indicators database, December 2005. 
DSTI/DOC(2006)9

\section{Manufacturing employment in non-OECD countries has not grown}

If manufacturing employment has fallen in OECD countries, the question can be raised what has happened in non-OECD countries? Have jobs been shipped off-shore? Although the available data are not readily comparable, ILO and UNIDO statistics suggest that the absolute number of manufacturing workers in non-OECD countries is considerably higher than in the OECD area. China alone had over 80 million manufacturing workers in 2002, which is similar to total manufacturing employment in the OECD area as a whole. On the one hand, this reflects the size and population of China, which outstrips that of the OECD. More importantly, however, the average level of productivity in Chinese manufacturing remains at a very low level (see below). Despite the large numbers of workers engaged in Chinese manufacturing, China (and many other non-OECD countries) still account for a (relatively) modest, through rapidly growing share, of global manufacturing production (see below).

The limited evidence on trends in manufacturing employment in non-OECD countries suggests that the decline in manufacturing employment in OECD countries has not been accompanied by an increase in non-OECD countries. ILO and UNIDO employment estimates for key non-OECD countries such as Brazil, China and Russia show that manufacturing employment has also declined in these countries, and very substantially in some of them. For example, a recent study (Conference Board, 2004b) cites a net job loss of more than 4 million jobs between 1995 and 2002 in China's manufacturing sector, while a recent BLS report suggests that manufacturing employment in China fell from 98 million workers in 1995 to 83 million in 2002 (Banister, 2005a). At the same time, manufacturing employment has remained relatively stable in other large countries such as India and Indonesia. The key factor responsible for the decline in manufacturing employment in these countries is therefore rapid productivity growth, notably in countries such as China and Russia, where economic restructuring has been accompanied by the closing of many inefficient state-owned plants (Conference Board, 2004b). This suggests also that the decline in manufacturing employment in OECD countries has not only been due to a shift of production from OECD to non-OECD countries. While this has certainly played a role for some countries and some industries, the key factor driving the decline in manufacturing employment is productivity growth.

\section{Manufacturing production and value added have continued to experience strong growth}

One possible source for the decline in manufacturing employment in OECD countries could be slow growth in the demand for manufacturing products, which could lead to slow growth in manufacturing production and value added. However, the available data point to strong growth in manufacturing production and value added, in particular in certain key OECD countries, such as Canada and the United States (Figure 7). In European countries, in particular in Germany, Italy and the United Kingdom, manufacturing value added has grown only little in recent years, which is also the case for Japan since the early 1990s. Outside the G7 countries, manufacturing value added in OECD countries increased particularly quickly in recent years in Finland, Hungary, Korea, Mexico, Poland and Sweden. 
Figure 7. Index of manufacturing value added, G7 countries, 1970-2003 Volume index (based on constant prices), $1980=100^{1}$

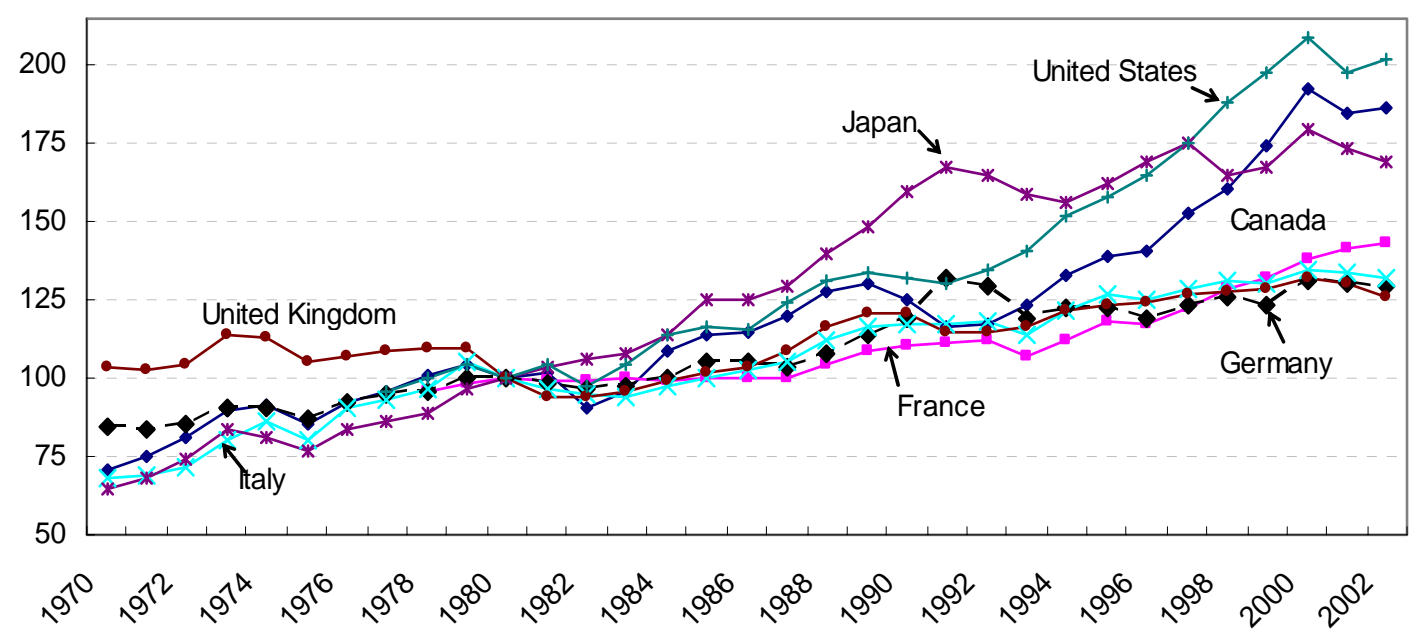

1. Data on value added is available for more countries in the OECD STAN database than data for production. For countries where both indicators are available, the trends are fairly similar.

Source: OECD, STAN database, December 2005.

While the volume of manufacturing production and value added has continued to rise over the past decades, the share of manufacturing in value added at current prices has slowly declined (Wölfl, 2005; Figure 8). From 1980 to 2003, the largest declines in shares occurred in the United Kingdom, Italy, Spain, Germany and France. From 1990 to 2003, the largest declines occurred in Luxembourg and Poland. Despite these declines, the manufacturing sector still accounted for $20 \%$ or more of value added in 2003 in several OECD countries, including Japan, Germany, Finland, the Czech Republic, Korea and Ireland. On the other hand, it had declined to less than $15 \%$ of total value added in Luxembourg, Norway, Greece, Australia, Iceland, the United Kingdom, the United States and the Netherlands.

To some extent, the declining share of manufacturing in value added is due to price effects. Since much of the manufacturing sector is characterised by relatively high productivity growth, prices of manufacturing products tend to increase only little over time and may even fall. This contrasts with the experience of the many parts of the services sector, where productivity growth has been slower and prices tend to go up more strongly over time. This price effect contributes to the declining share of manufacturing in value added; while manufacturing production has continued to increase, manufacturing products have become relatively cheap and therefore account for a smaller proportion of the economy than they did before. 
Figure 8. Share of manufacturing value added in total economy, 1980-2003*

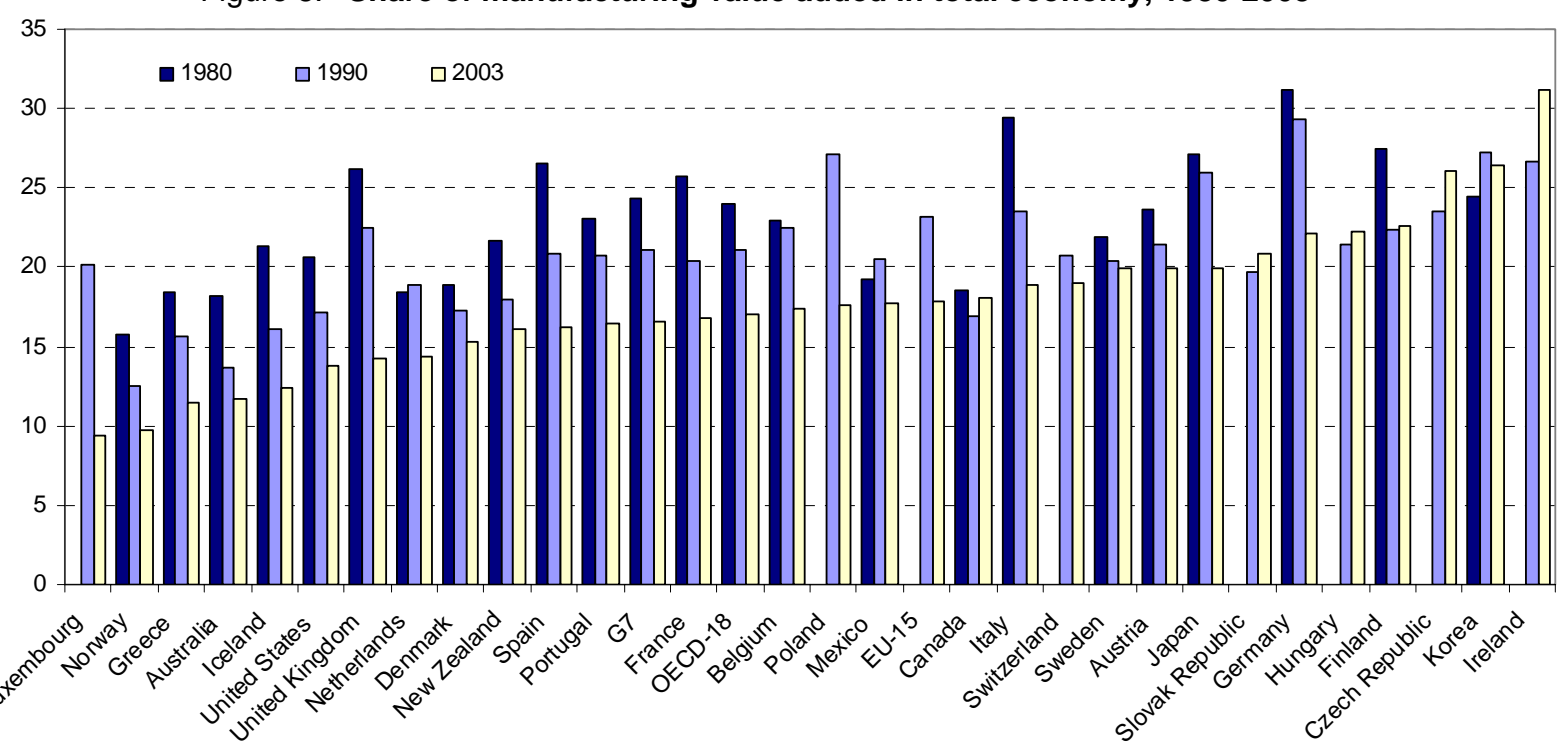

*) Or latest available year.

Source: OECD, STAN Indicators database, April 2006.

The decline in value-added shares is also reflected in the share of high and medium-high technology manufacturing industries (Figure 9). In 2002, high and medium-high technology manufacturing accounted only for about $7.5 \%$ of total OECD value added, compared to about $8.5 \%$ in 2000 (OECD, 2005). In the United States, the share fell from $7.5 \%$ in 1990 to $6.0 \%$ in 2003. In Japan, it fell over the same period from $12.2 \%$ to $9.7 \%$, and in the EU-15 (excluding Ireland and Luxembourg), it fell from $9.2 \%$ to $7.8 \%$. Some countries experienced increases in the importance of these sectors, however. In Ireland, the importance of high and medium-high technology manufacturing rose from $11.4 \%$ in 1990 to $20.8 \%$ in 2002. In Korea, the rise was from 12.1 in 1990 to 14.7 in 2003; in Hungary, from 6.4\% in 1994 to 9.6\% in 2002; and in the Czech Republic, from 6.6\% in 1994 to $10.3 \%$ in 2003.

Figure 9. Share of high and medium-high technology in total gross value added, 1990-2003*

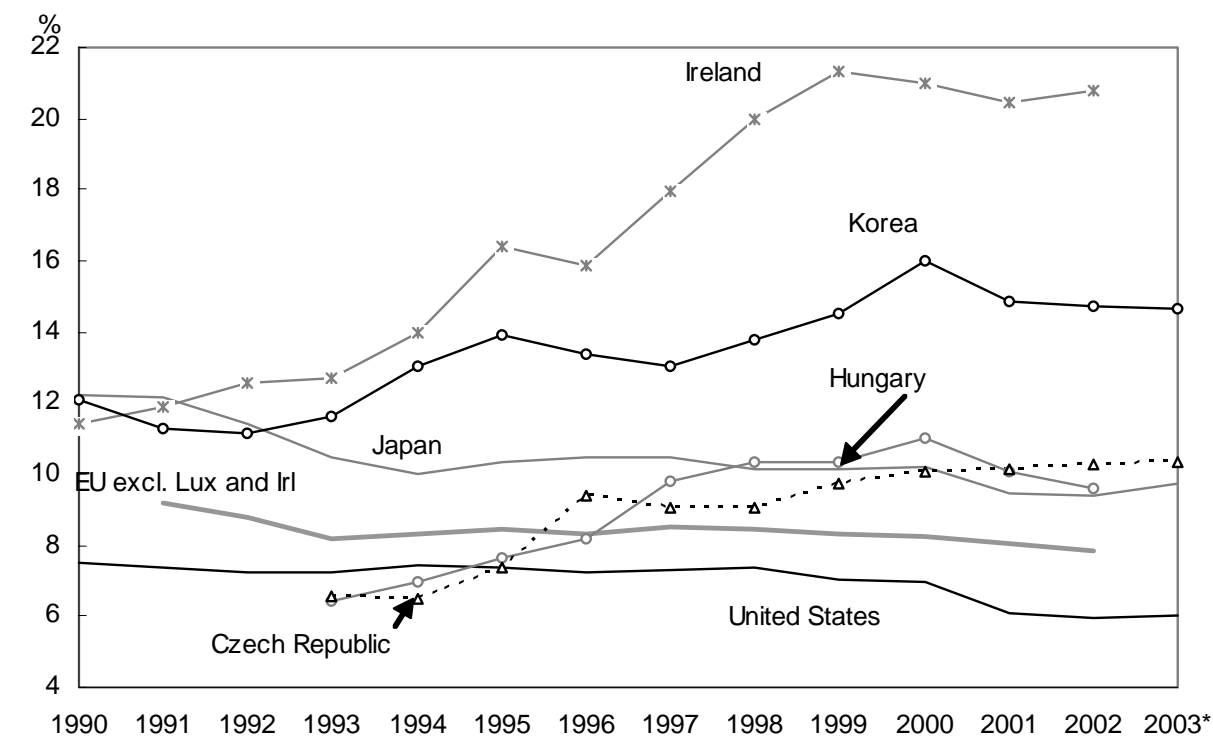

Note: *) Or latest available year.

Source: OECD, STAN Indicators database, December 2005. 


\section{Demand for manufacturing goods remains high}

Manufacturing is also important for the economy since it provides important inputs to other sectors of the economy and since it satisfies a broad range of final and intermediate demands. Evidence on the importance of manufacturing in this respect can be derived from input-output tables. Figure 10 shows that final demand for manufacturing products in the mid-1990s accounted for between $45 \%$ and $50 \%$ of total final demand in the Czech Republic, Hungary and Korea. In Australia, Norway and the United States, this share had declined to about 22\%-26\% of total final demand by 1995 . For countries for which input-output tables are available over a long time period, the data suggest a gradual decline of the share of manufacturing demand in total final demand. At the same time, these shares are considerably higher than the shares of manufacturing in value and employment, and show that manufacturing still accounts for a considerable share of overall economic activity. ${ }^{1}$

Figure 10. Share of final demand for manufacturing goods as a share of total final demand, 1970-1995 ${ }^{1}$

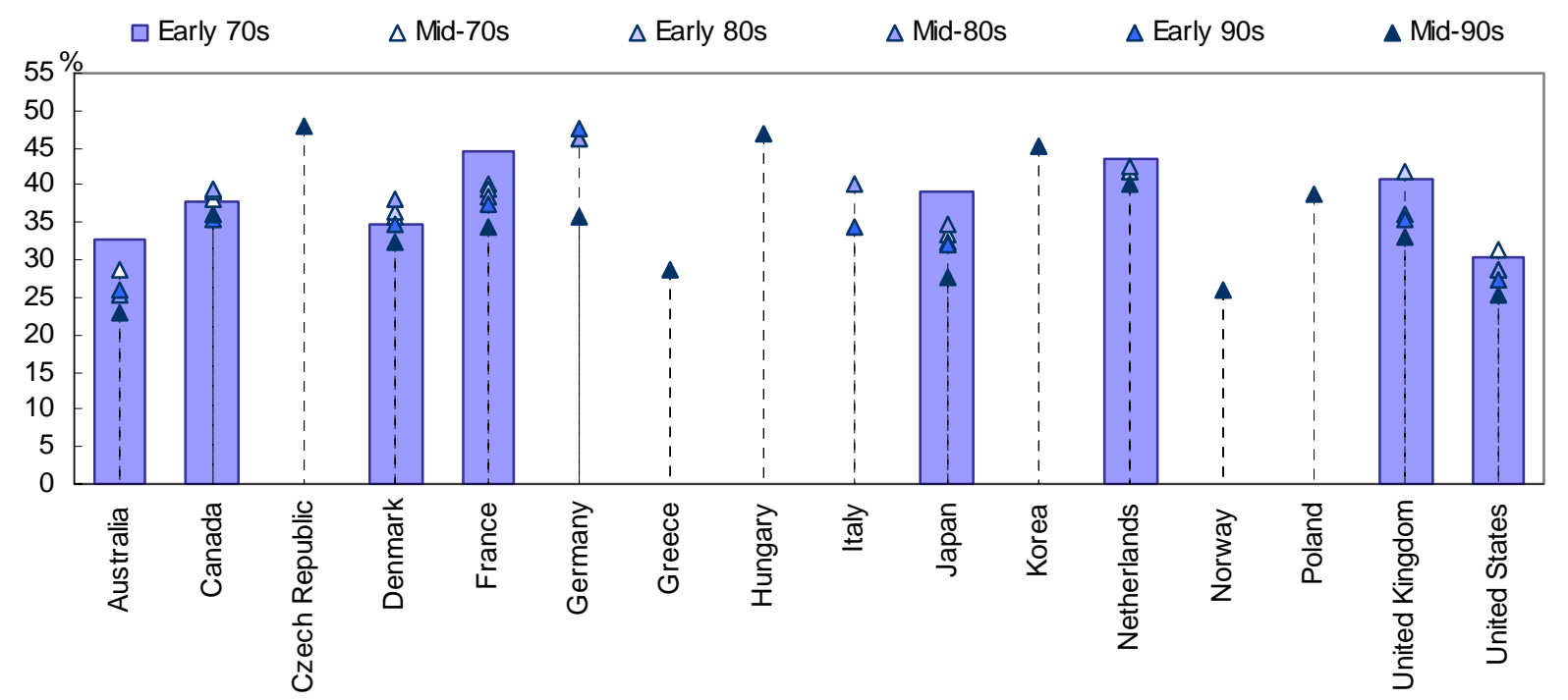

Source: OECD, Input-Output Tables database.

Another way of illustrating the role of manufacturing in demand is by examining the share of demand for manufacturing in total demand (intermediate and final demand). These shares are shown in Figure 11, which points to very high shares for the Czech Republic, Hungary and Korea (over 50\% in Korea), with the lowest shares (28\%-30\%) for Australia, Norway and the United States. This illustrates once more that manufacturing remains considerably more important to total economic activity than suggested by other indicators, such as value added shares.

1. Work is currently underway at the OECD to update its Input-Output Tables to 2000 or a later available year. Once this work is complete, the estimates in Figures 10 and 11 can be updated to a more recent period. See Yamano and Ahmad (2006) for further details on this work. 
Figure 11. Share of total demand for manufacturing goods as a share of total demand, 1970-1995

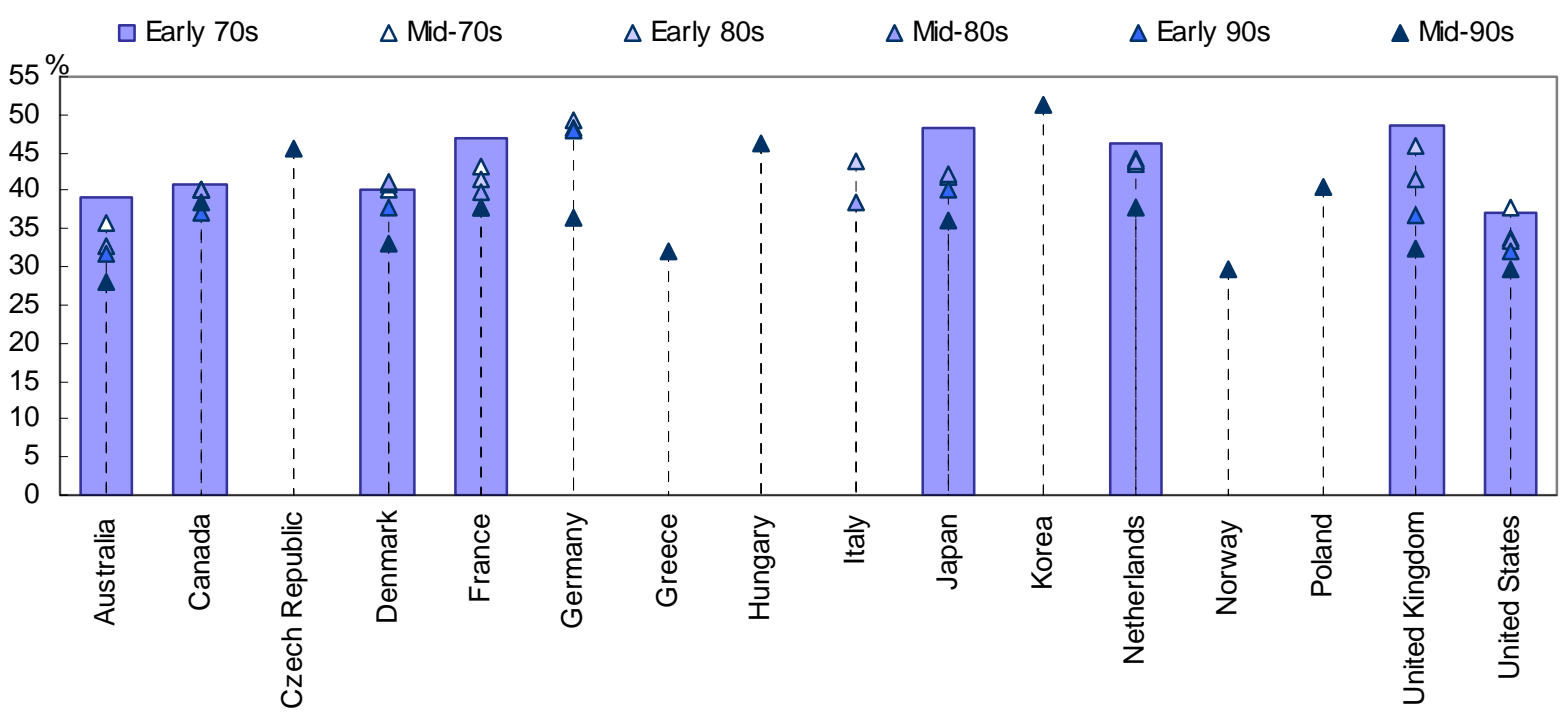

Source: OECD, Input-Output Tables database.

\section{Global production continues to rise}

Output growth of manufacturing products in certain non-OECD countries, such as China, has been particularly rapid in recent years. In terms of the importance of different countries in global manufacturing, OECD countries still dominated global manufacturing in 2002, however, accounting for just below $80 \%$ of world-wide manufacturing (Figure 12). China accounted for about $8 \%$, however, which is similar to Germany's share in that year. The share of other Asian countries was about the same as that of China in 2002, while South America accounted for about $4 \%$ of global manufacturing, a share comparable to that of the United Kingdom or France. Africa accounted for only 1.3\% of manufacturing value added in 2002, a share comparable to that of Chinese Taipei.

Figure 12. Share in world manufacturing value added, 2002, in $\%^{1}$

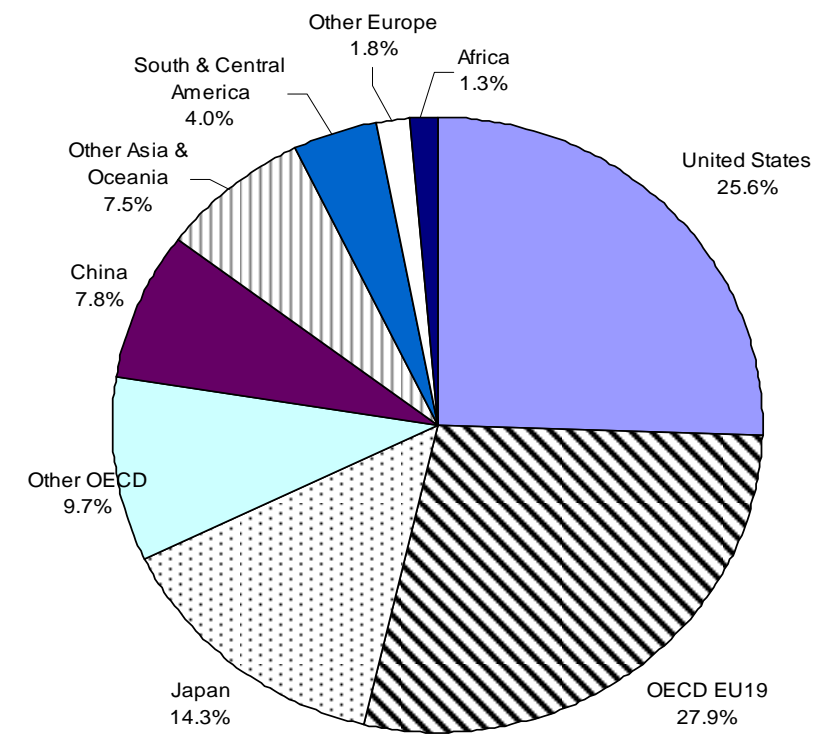

1. Data on value added are converted at exchange rates. The estimates should be interpreted with caution.

Source: OECD, STAN database and UN Statistics Division. 
Figure 13 shows that out of the 10 top global manufacturing countries in 2002, 9 belonged to the OECD, with US and Japanese manufacturing being the largest. In 2002, China's manufacturing value added was about the same as that of Germany. Given recent trends, China has now clearly become the third-largest manufacturing country in the world. Other non-OECD countries, including Brazil, India and the Russian Federation, only accounted for a small share of global manufacturing in 2002.

Figure 13. Top 20 manufacturing countries, 2002, in million dollars ${ }^{1}$

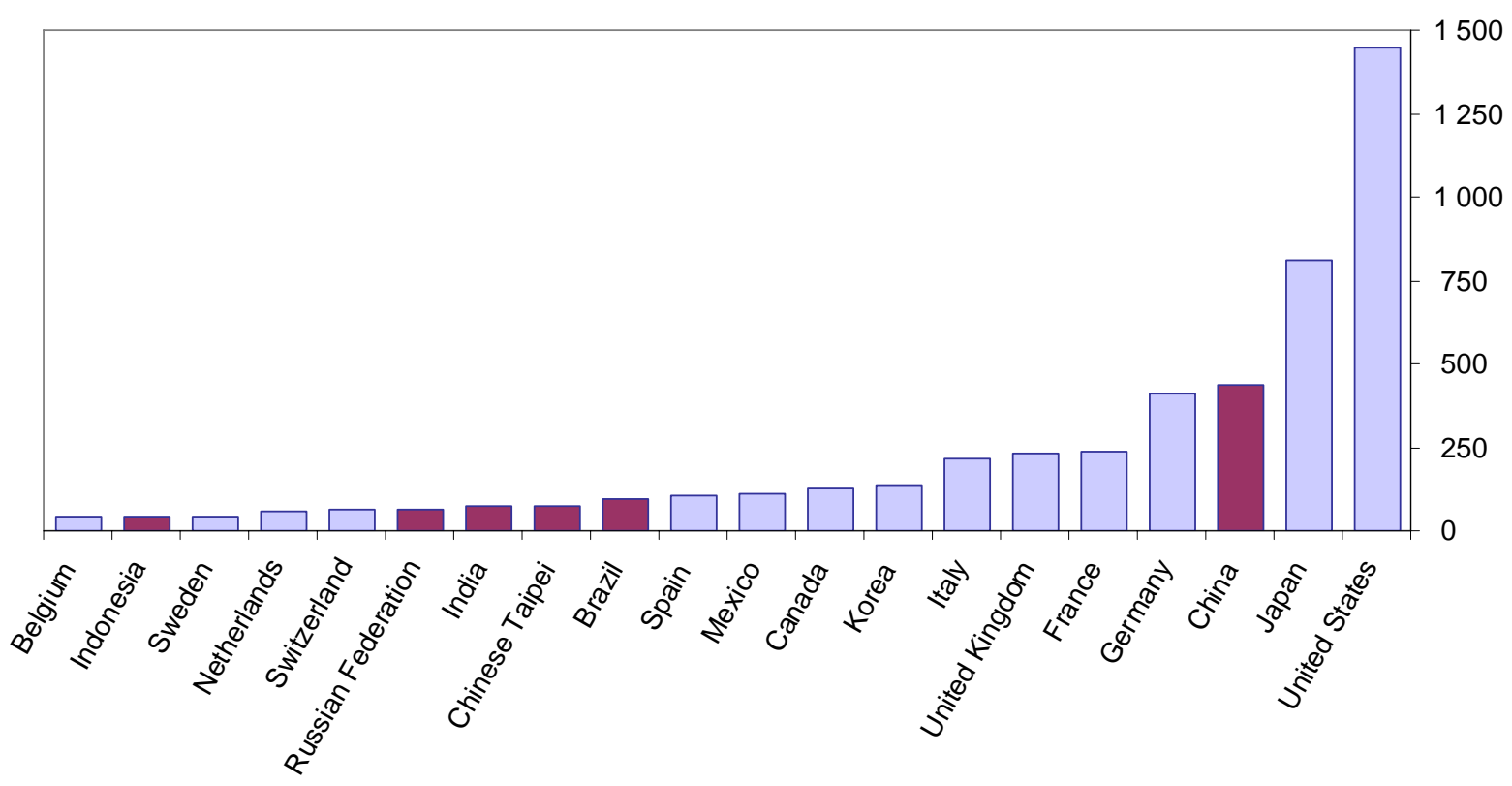

1. Data on value added are converted at exchange rates. The estimates should be interpreted with caution.

Source: OECD, STAN database and UN Statistics Division.

The share of China in global manufacturing has risen rapidly over the past few decades, as is shown in Figure 14. Strong growth has also occurred in East Asia, whereas South Asia and the Middle East have also experienced a growing share in world manufacturing. At the same time, the share of Latin America has declined whereas that of Africa has remained at a very low level. 
Figure 14. Share of major developing regions in global manufacturing value added, in \%

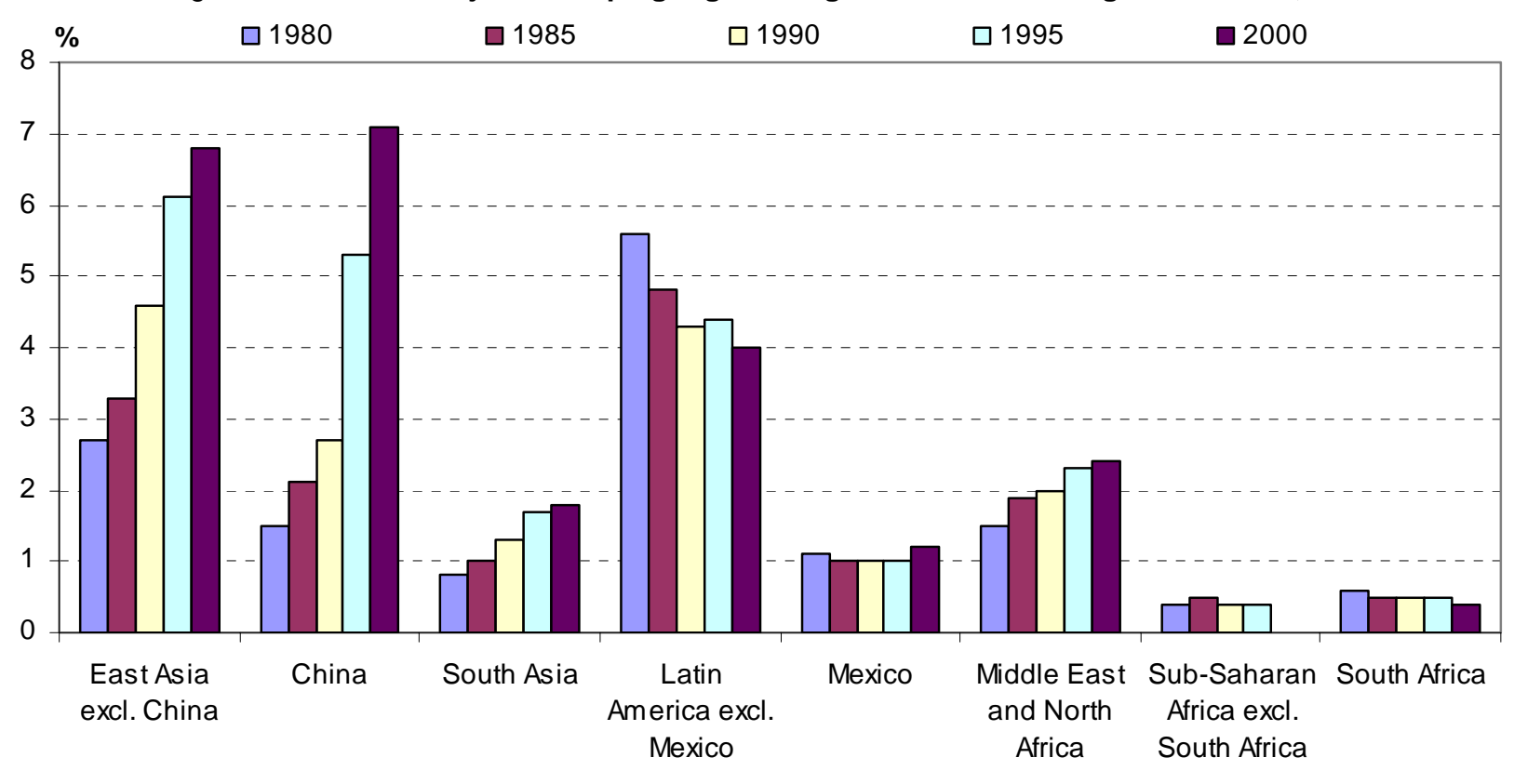

Source: UNIDO (2004).

\section{Trends in the internationalisation of manufacturing}

\section{Manufacturing trade is increasing more rapidly than global production}

The growth of manufacturing production is accompanied by an even faster growth of manufacturing trade, in particular of high-technology goods. This is visible in the growing export intensity of manufacturing production; for total manufacturing, this has increased considerably for all OECD countries from 1990 to 2003 (Figure 15a). A similar increase can be observed for high-technology industries, where the level of export intensity is even higher (Figure 15b). Similar increases in the trade intensity of manufacturing can be observed for imports. Both indicators point to a growing integration of manufacturing production at the global level. ${ }^{2}$

2. Note that the high shares of exports in production for Belgium and the Netherlands are linked to re-exports. Recent research indicates that $40 \%$ of total exports in the Netherlands should be considered as re-exports (i.e. the re-export of imported goods without being significantly processed). 
Figure 15. Share of exports in production, 1990-2003 ${ }^{1}$

a) Total manufacturing

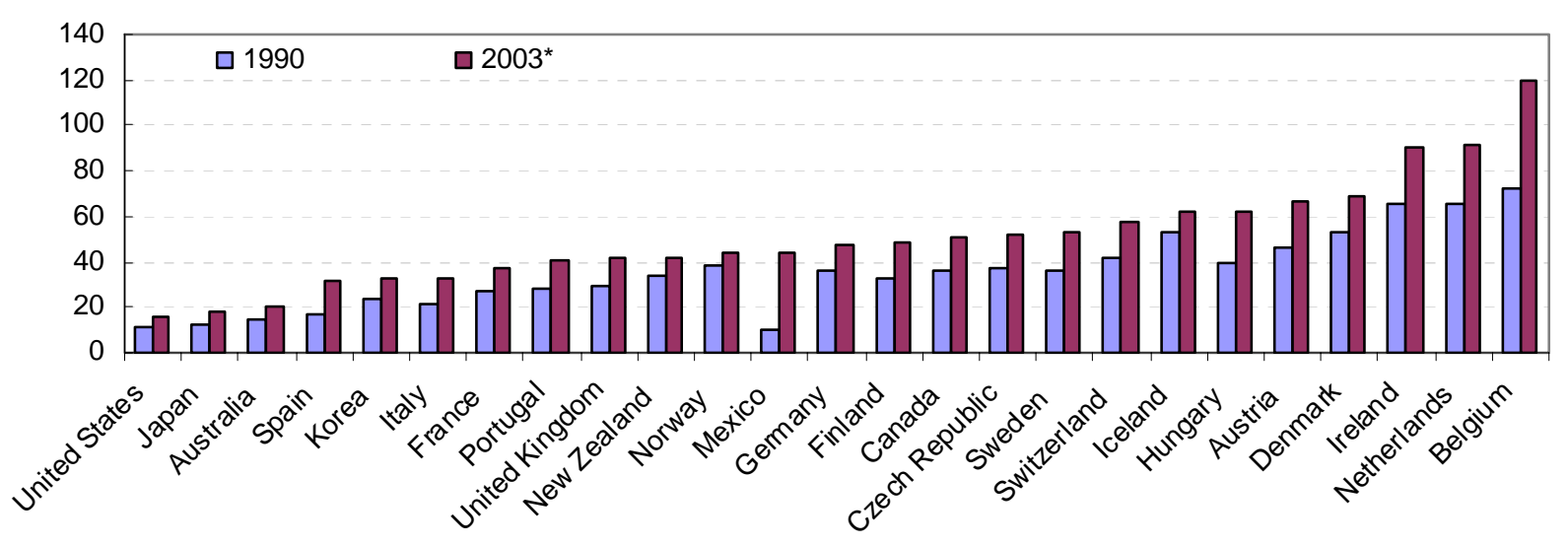

b) High-technology industries

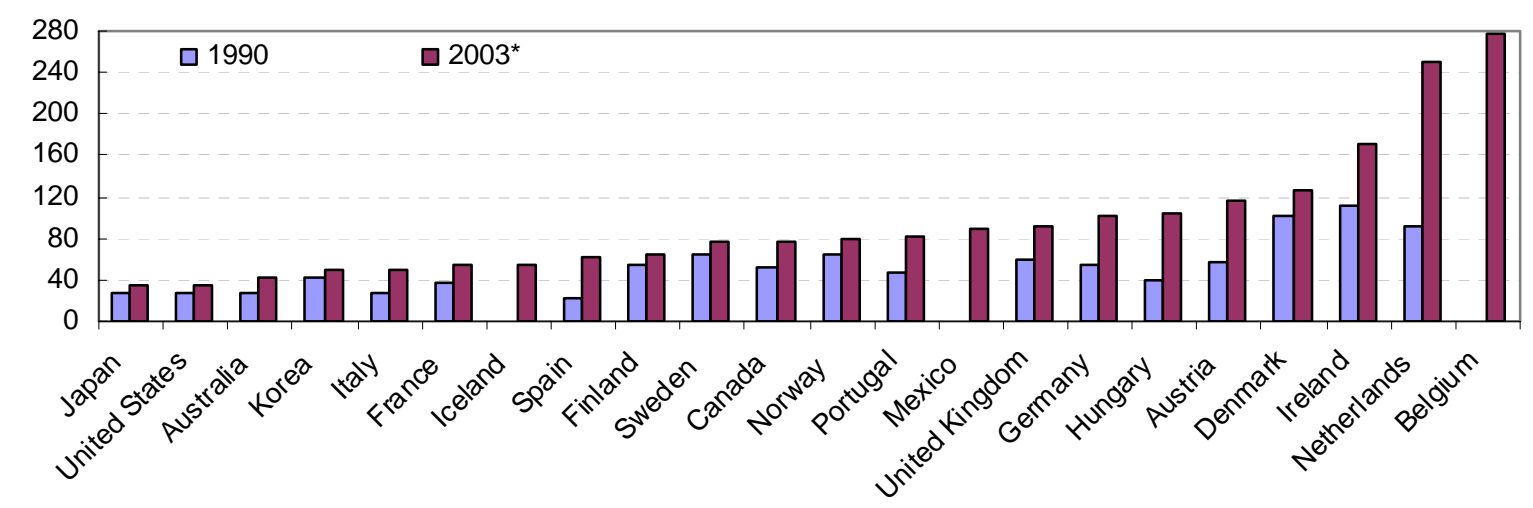

1. Or latest available year.

Source: OECD, STAN Indicators database, December 2005.

Inter-industry trade is important, pointing to the integration of value chains

Much manufacturing trade occurs within the same industry or even within a firm, resulting from the integration of manufacturing production throughout the value chain. Such simultaneous exports and imports within the same industry are generally labelled as intra-industry trade (see OECD, 2005b). It typically occurs among rich countries with similar levels of development which are geographically close, and is often regarded as a corollary of smooth economic integration. Countries in which intra-industry trade is high in relation to aggregate manufacturing trade (over 70\%) and where it has increased in recent years are the Czech Republic, Hungary and Portugal (Figure 16). In some other countries, such trade remains fairly important, although it has not increased significantly. These countries include France, Canada, Austria and Switzerland. 


\section{DSTI/DOC(2006)9}

Figure 16. Manufacturing intra-industry trade as a percentage of total manufacturing trade Average 1996-2003

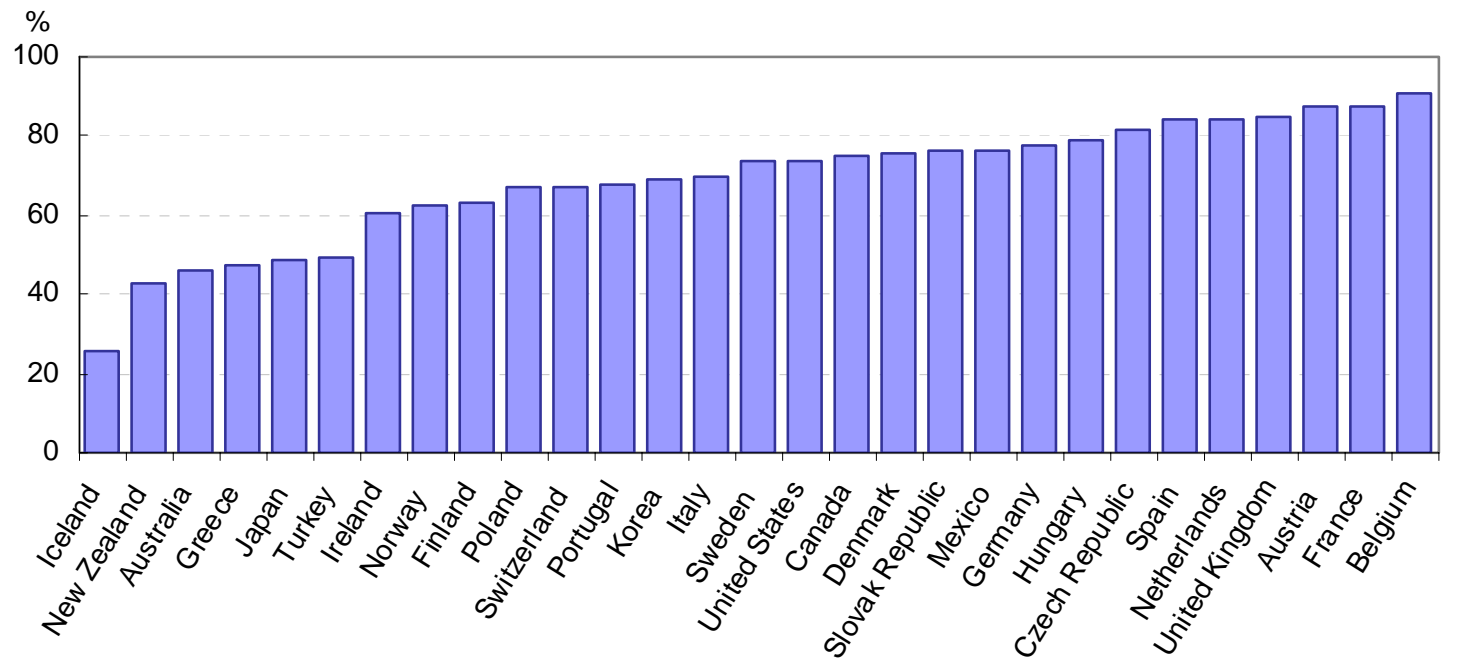

Source: OECD, STAN Indicators database, June 2005.

The high level and fast growth of intra-industry trade in some Central and Eastern European countries may stem from the large volume of direct investment in those countries, from Germany in particular. The shift to these countries of numerous activities of foreign multinationals was conducive to a relatively swift rise in intra-industry trade over the course of the 1990s. The low level of intra-industry trade in Japan may be due to the fact that Japanese exports are concentrated in a number of high-technology sectors that generate substantial trade surpluses.

\section{There are winners and losers in the global market place}

The growth of global manufacturing trade has boosted trade in most OECD countries, but does not benefit all countries equally. Some countries have gained market share, while others have lost market share. Over the period 1995 to 2003, among the G7 countries, Japan, the United States, the United Kingdom, France and Italy lost export market shares in goods, while Germany and Canada increased theirs (Figures 17b). The highest growth of export market shares in goods is observed for Hungary, Ireland, Greece, the Slovak Republic, Poland, the Czech Republic, Mexico and Turkey. Despite these increases, these countries still account for only a small share of world export market shares (Figure 17a). 
Figure 17. Trends in export market shares in goods

Figure 17a. World export market shares in goods of OECD countries, 2003

Current prices

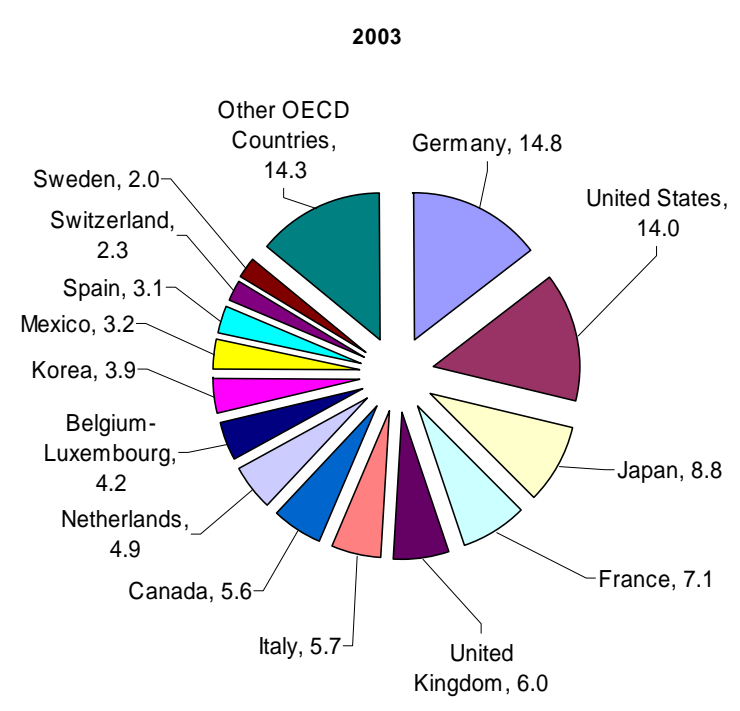

Figure $17 b$. Growth of OECD countries export market shares in goods between 1995 and 2003

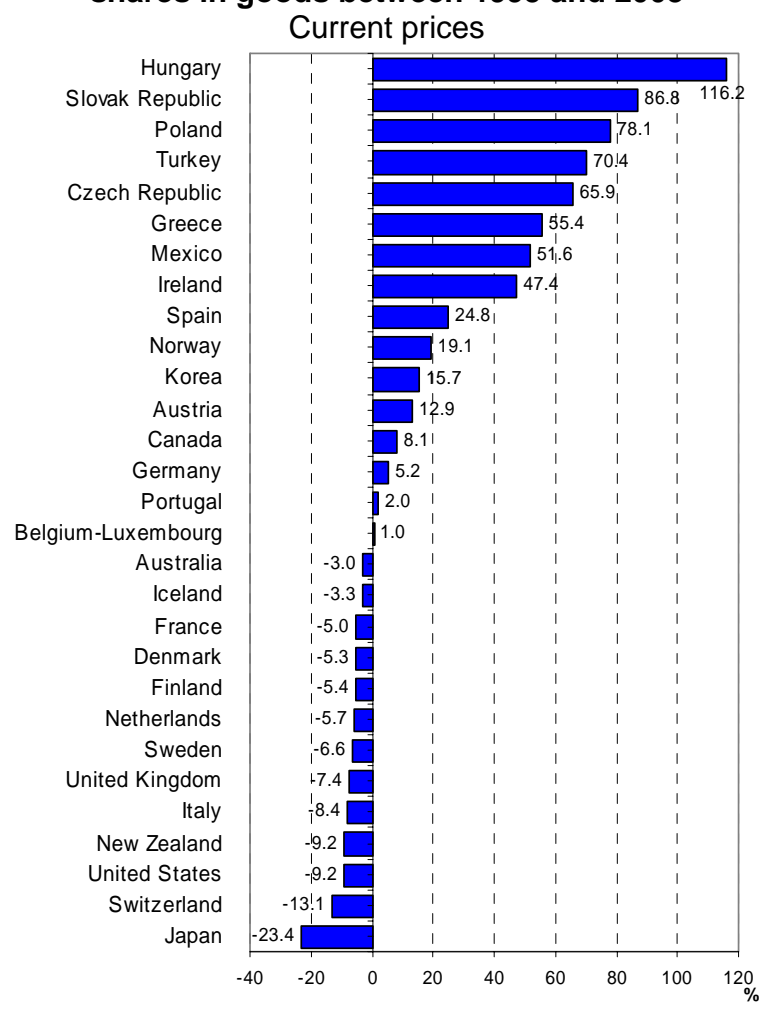

Source: IMF, Balance of Payments Statistics, April 2005; OECD, Economic Globalisation Indicators, 2005.

\section{The comparative advantage of OECD countries differs considerably}

OECD countries differ considerably in the composition of manufacturing trade and in their relative comparative advantage. This is illustrated in Figure 18, which shows the relative strengths of different OECD countries in terms of their trade package, classified according to the technology intensity of their trade package (see OECD, 2005c). Only a few OECD countries, notably Switzerland, Ireland, the United States and the United Kingdom have a strong comparative advantage in high-technology manufacturing. Several others, notably Japan and Germany, are particularly strong in medium-high technology industries, such as machinery, electrical equipment and cars. Yet another group of countries, including Portugal, Turkey, Iceland and New Zealand have a particularly strong comparative advantage in low-technology manufacturing. 


\section{DSTI/DOC(2006)9}

Figure 18. Contribution to the manufacturing trade balance, 2003

As a percentage of total manufacturing trade

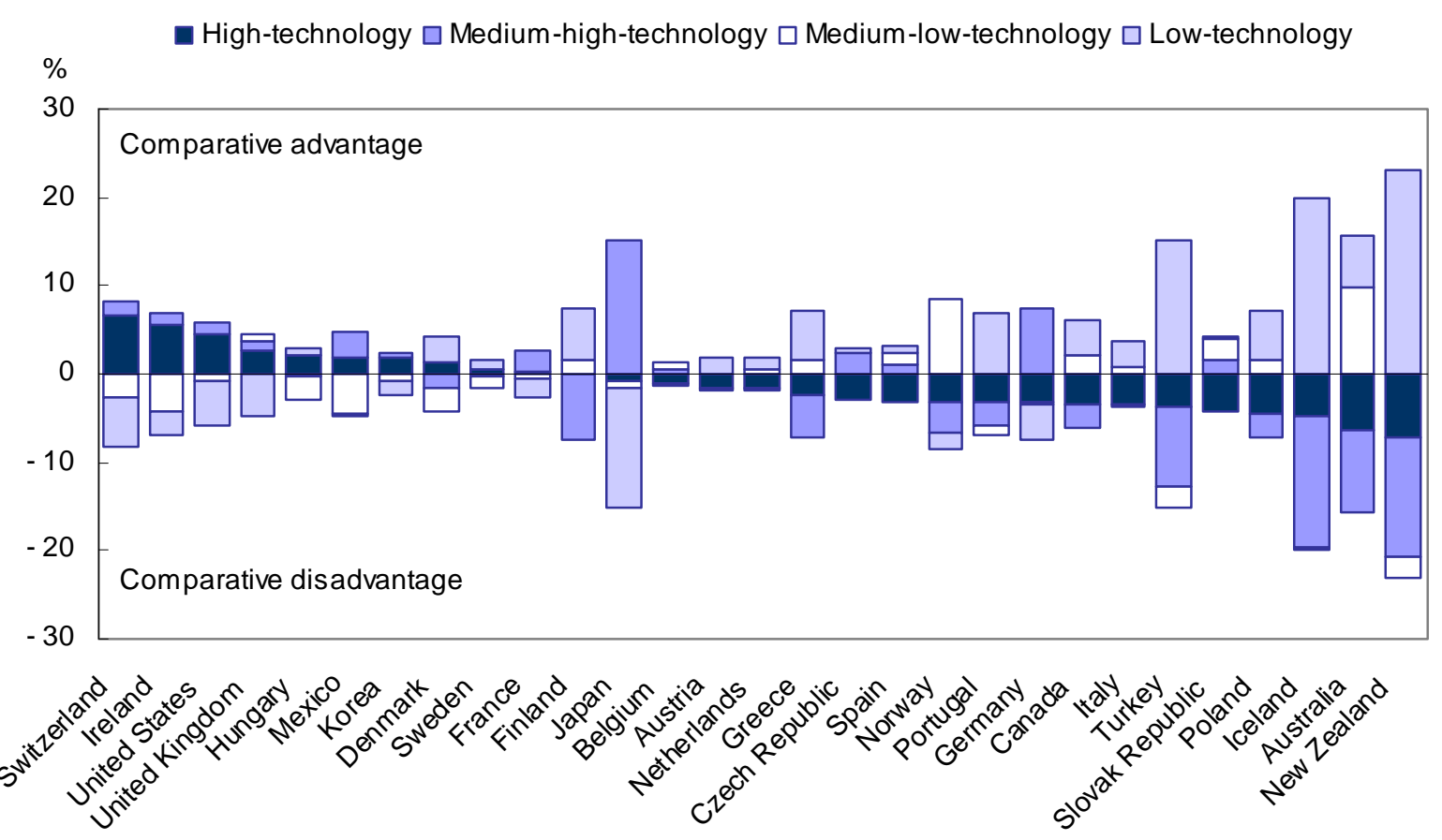

Source: OECD, STAN Indicators database, June 2005.

Figure 19. Share of high and medium-high technology industries in manufacturing exports, 2003 As a percentage of total manufacturing exports
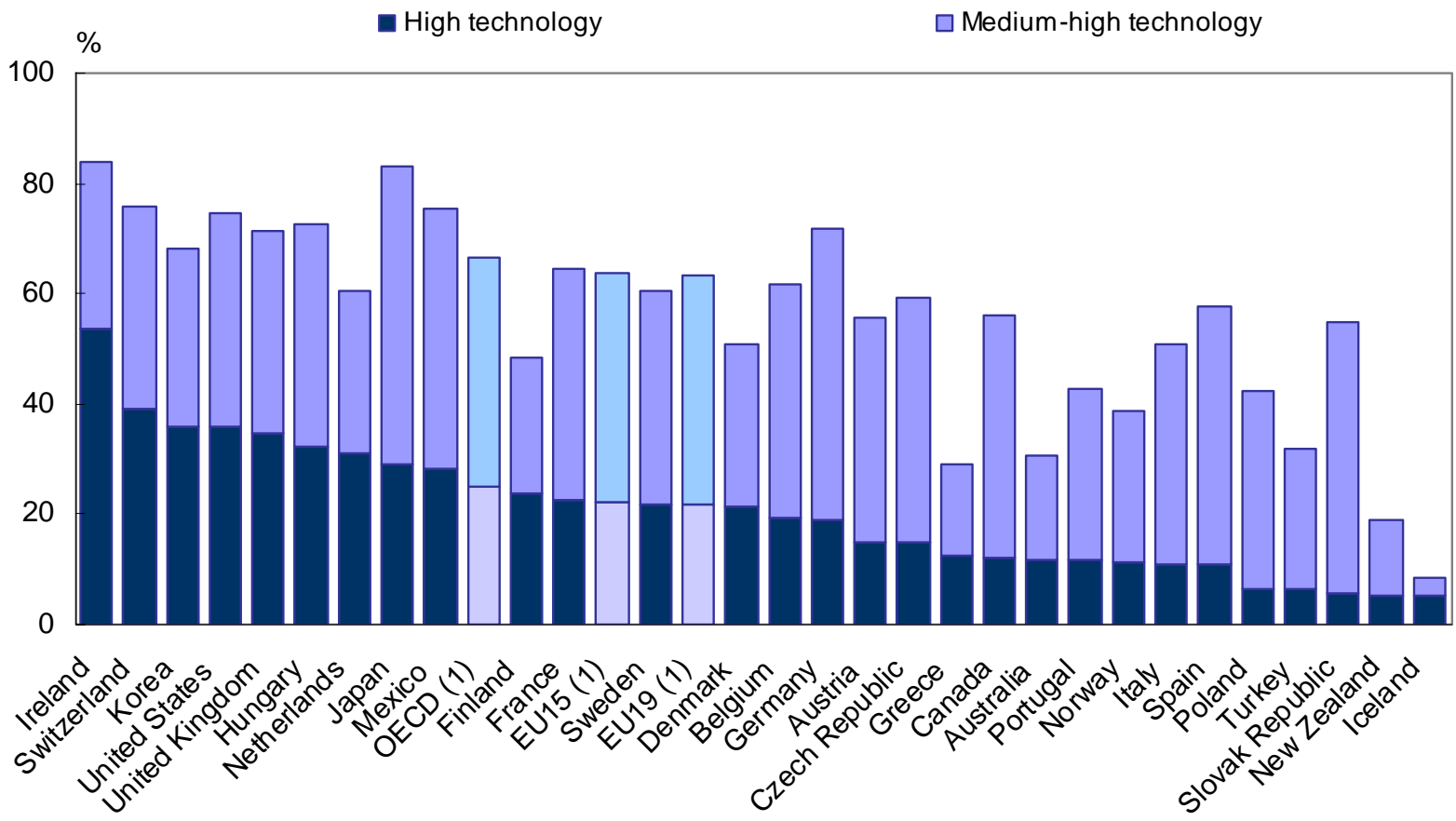

1. Excluding Luxembourg.

Source: OECD, STAN Indicators database, June 2005. 
Another way of illustrating the relative strengths of different OECD countries is the share of different industries in manufacturing exports (Figure 19). This shows very high shares of high-technology industries in Ireland (58\% of total manufacturing exports), Switzerland, the United States, the United Kingdom and Korea. Japan, Germany, Mexico and Spain have particularly high shares of medium-high technology industries in total manufacturing exports.

These patterns of comparative advantage are not static, but are slowly changing over time, as the structure of OECD economies adjusts and firms engage in new activities. Some evidence for the changing pattern of comparative advantage from 1994 to 2003 is presented in Figure 20. For the high-technology industries, it shows large shifts for Finland, Hungary and Japan, where the first two countries strengthened their position in these industries, whereas Japan lost some of its edge in this part of the market. For medium-high technology industries, large shifts can be observed for Greece, the Czech Republic, Hungary, the Slovak Republic, Ireland, Korea, Portugal and Turkey, with all these countries reducing their comparative disadvantage in this part of the global market.

Figure 20. Changes in the contribution to the manufacturing trade balance, 1994-2003 As a percentage of total manufacturing trade

High technology industries

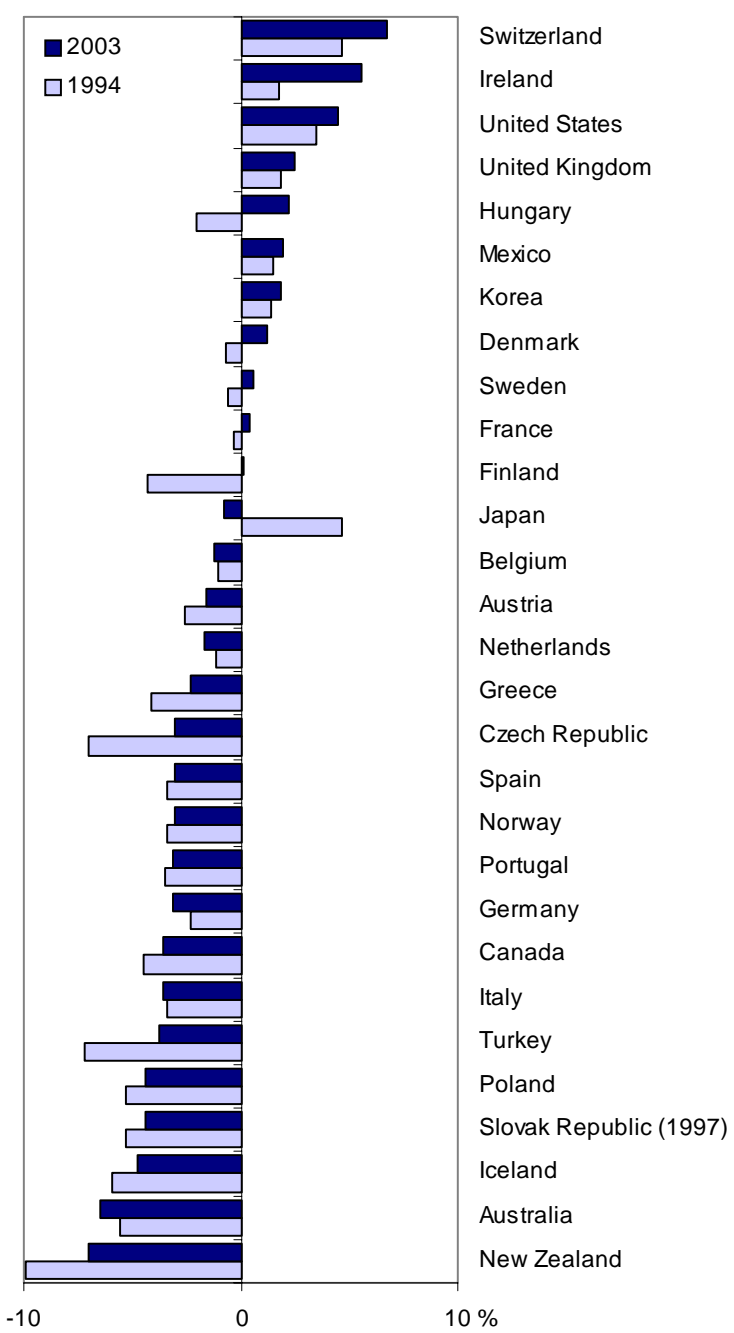

Note: No data are available for Luxembourg.

Source: OECD, STAN Indicators database, September 2005.

\section{Medium-high-technology industries}

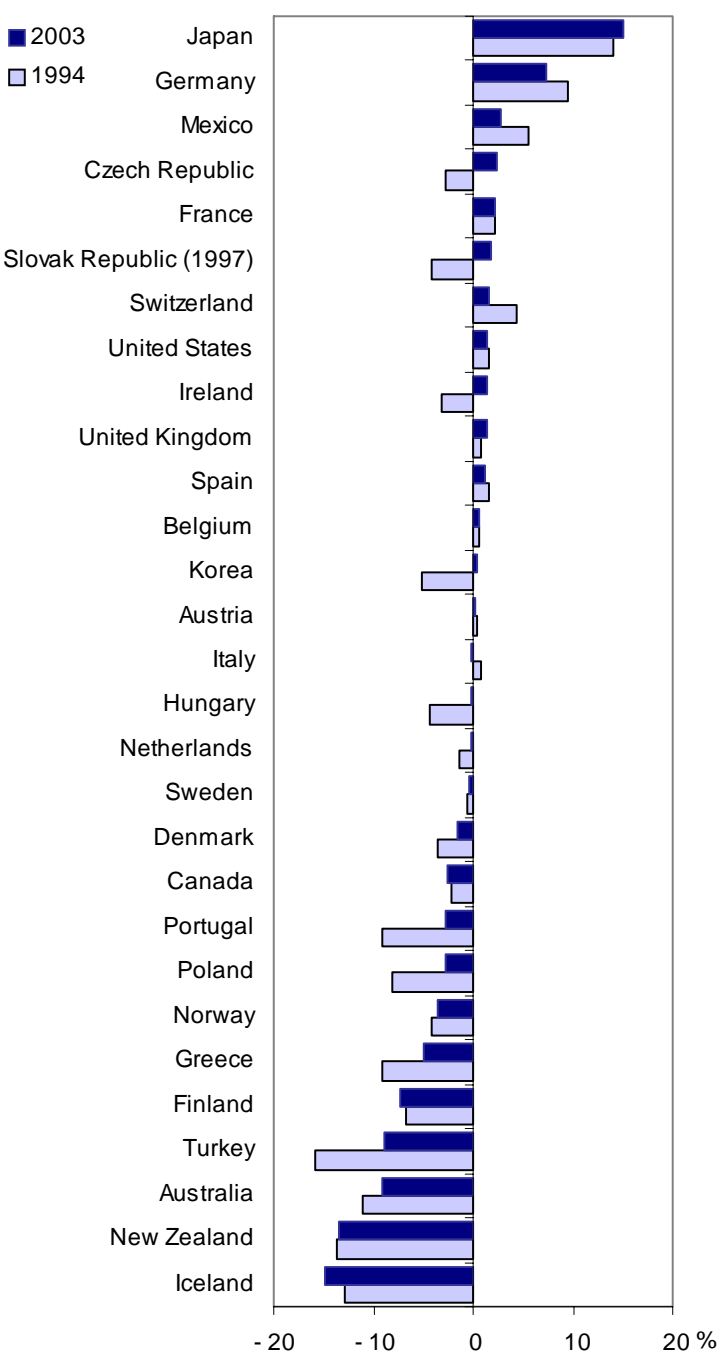




\section{Foreign affiliates are of growing importance}

Much of global trade is carried out by MNEs and much trade takes place between MNEs and their foreign affiliates, in the form of intra-firm trade. Data on such intra-firm trade is only available for some OECD countries (Figure 21). The share of intra-firm exports in total exports of manufacturing affiliates under foreign control ranges between $15 \%$ and $60 \%$ in the OECD countries for which such data are available. Throughout the 1990s and the beginning of the present decade, this proportion held steady at around $50 \%$ in the United States, Canada and the Netherlands, but rose sharply in Sweden (from 35\% to $75 \%$ ) and declined in Japan (from 35\% to 15\%). In other words, in 2001, only 30\% of the exports of affiliates under foreign control in Sweden were destined for non-affiliates, while in Japan the corresponding proportion was $85 \%$. This once more points to the growing integration of production in value chains, where parts of production are being relocated to other countries.

Figure 21. Share of intra-firm exports in total exports of affiliates under foreign control, 1990-2001

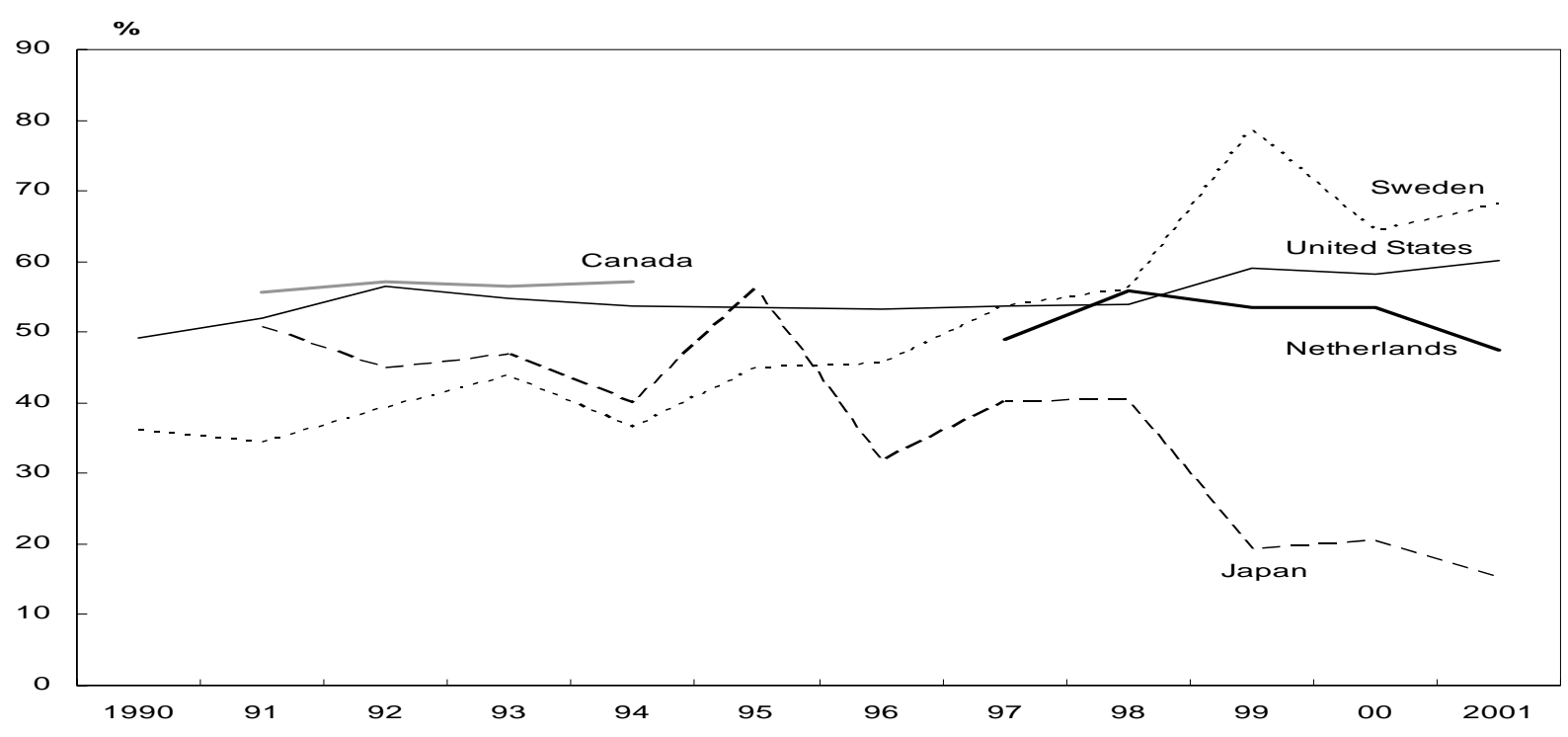

Source: OECD (2005), Economic Globalisation Indicators, Paris.

\section{Factors driving manufacturing performance}

The previous two sections of this paper have pointed to continued growth of manufacturing output, rapid growth in manufacturing trade, including a growing share of certain non-member economies, a declining share of manufacturing in OECD demand, GDP and employment, as well as an absolute decline in the number of manufacturing workers. This section examines some of the factors that underpin these trends. This includes productivity and labour costs, innovation and technology, and the interaction between services and manufacturing.

\section{Productivity growth in manufacturing remains high in many OECD countries}

One of the key drivers of manufacturing output and employment is rapid growth in productivity, in particular in certain countries and industries. Average productivity growth rates in certain countries, notably Hungary, Korea, Poland and Sweden have been over 6\% annually (Figure 22). Combined with somewhat slow growth in manufacturing demand, high rates of productivity growth can contribute to a decline in manufacturing employment. In most OECD countries, average rates of productivity growth in manufacturing have been more modest, ranging between $2 \%-4 \%$ annually. This is still substantially higher than economy-wide growth in productivity, however (Wölfl, 2005). 
Figure 22. Productivity growth in manufacturing, $1980-90$ and $1990-2003^{*}$

Annual average growth of value added per person employed, in \%

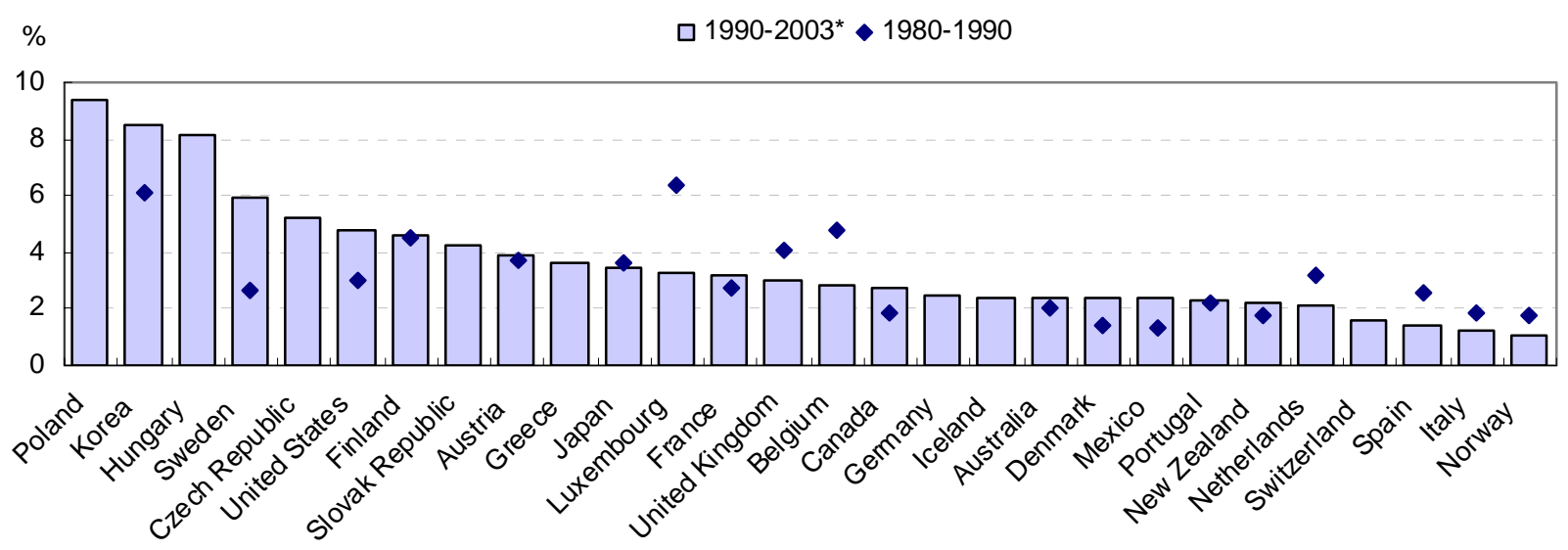

Note: * Or latest available year.

Source: OECD, STAN and STAN Indicators databases, December 2005.

Due to its high rates of productivity growth, the manufacturing sector continues to make a significant contribution to aggregate productivity performance, despite is relatively small share in total value added and employment. This is particularly the case in Finland, Hungary, Korea, Poland, the Slovak Republic and Sweden, where manufacturing made a large contribution to the high productivity growth rates characterising these countries over the past decade (Figure 23). However, manufacturing also accounted for the bulk of aggregate productivity growth in several other countries, including France, Japan and the Netherlands. In several other OECD countries, including Australia, Denmark, Greece, Norway, Portugal and the United Kingdom, however, manufacturing accounted for only a small share of aggregate productivity growth over the past decade.

Figure 23. Contribution of manufacturing to aggregate productivity growth, 1990-2003*

Contribution to annual average growth of value added per person employed, in \%

$\square$ Manufacturing $\square$ Services $\square$ Other industries

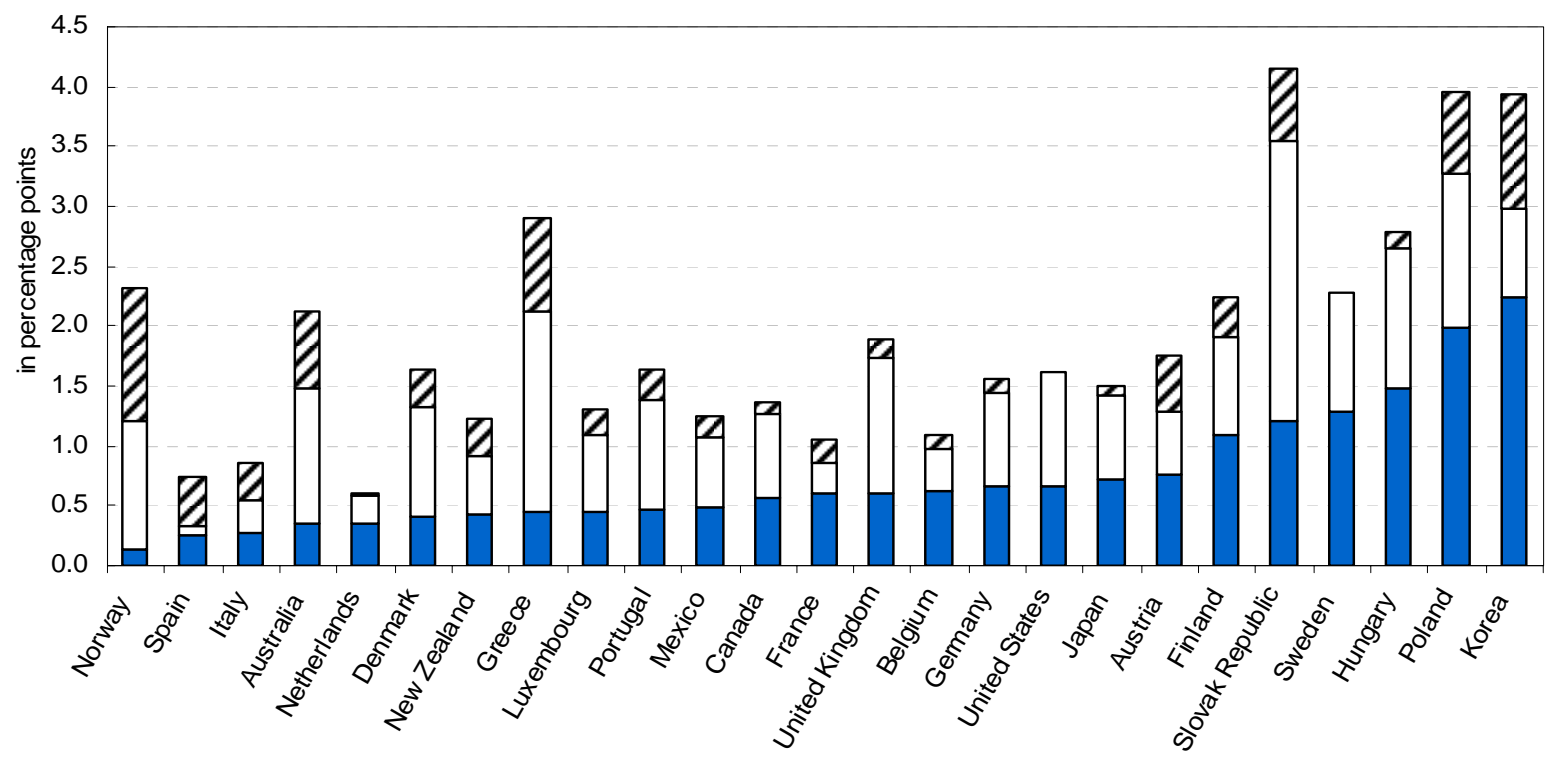

Note: * Or latest available year.

Source: OECD, STAN and STAN Indicators databases, December 2005. 


\section{DSTI/DOC(2006)9}

A closer look at the detailed industries underlying strong manufacturing productivity growth points to a diversity of experiences, reflecting relative strengths and weaknesses of different countries. In certain OECD countries, notably Finland, Hungary, Ireland, Japan, Korea, Sweden and the United States, ICTproducing industries have made a large contribution to aggregate productivity growth over the past decade (Pilat and Wölfl, 2004; Pilat, 2005).

\section{Gaps in productivity levels across countries are large and persistent}

Figure 24. Relative labour productivity in manufacturing, 1950-2000 GDP per hour worked, United States $=100$
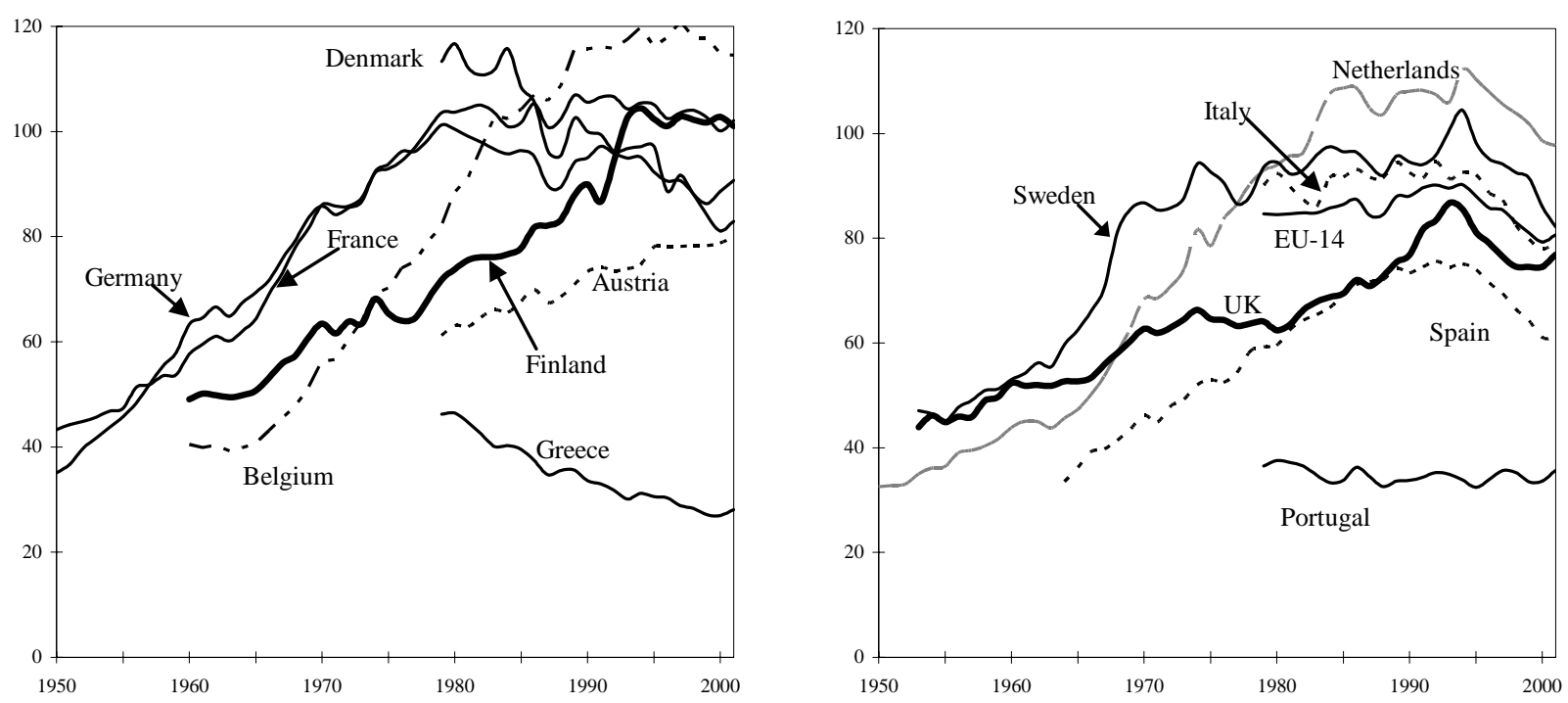

GDP per person employed, United States $=\mathbf{1 0 0}$
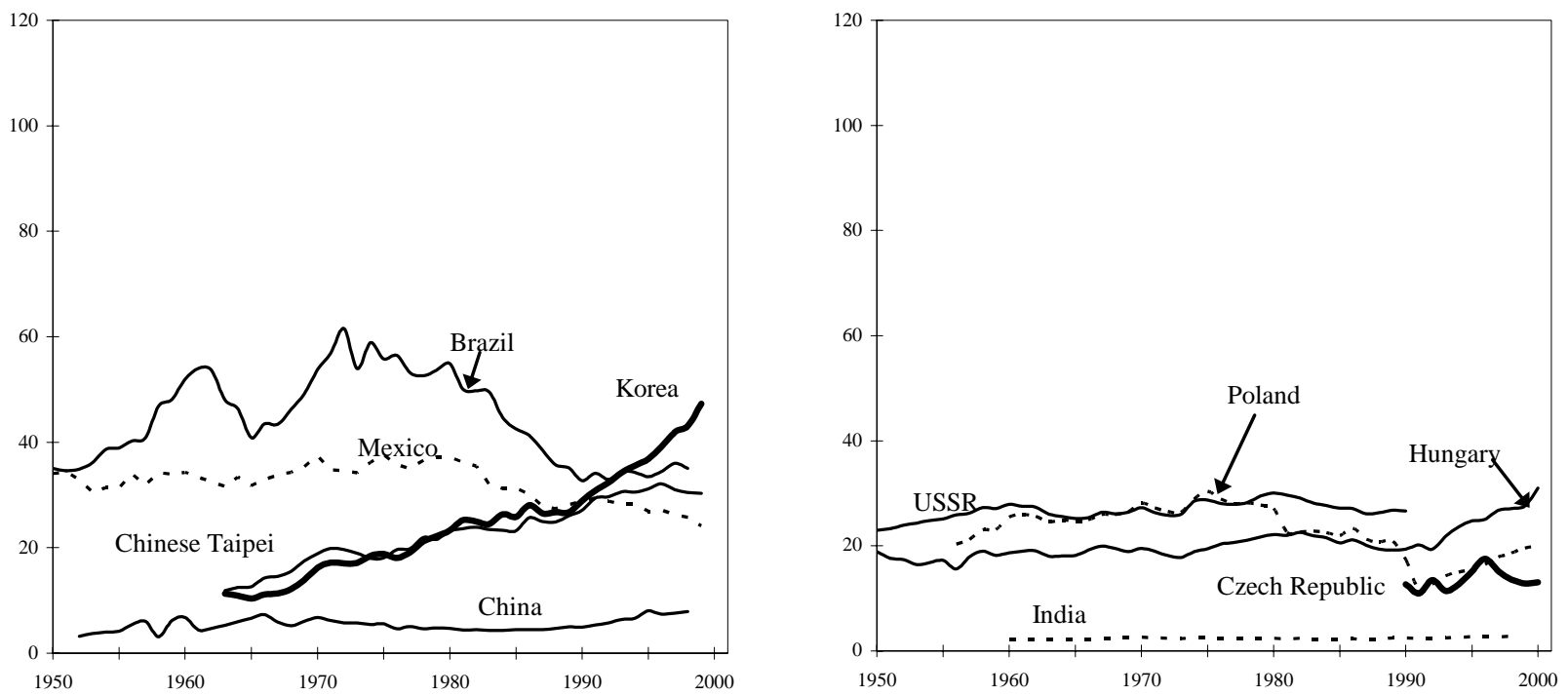

Source: Groningen Growth and Development Centre.

While manufacturing productivity has grown quickly in many OECD countries, the available evidence points to large and persistent gaps in productivity levels across OECD and non-OECD countries (Figure 24). Some countries, such as Finland and Korea, have made sizeable progress in catching up in productivity levels over the past decades. In others, little progress has been made and in some, notably in 
Europe, productivity levels compared with the United States have fallen over the recent period. The available evidence points to relatively low productivity levels for some non-OECD countries, notably China and India.

\section{Labour costs differ enormously across countries, but also reflect productivity gaps}

Labour costs are another key factor in determining the location of manufacturing production in different countries. Although labour costs account for only a fraction of total manufacturing costs (with considerable differences across industries), it is one of the factors that is most linked to location, as it is influenced by domestic labour market conditions. Comparisons of manufacturing labour costs are published on a frequent basis by the US Bureau of Labor Statistics. These comparisons cover 25 OECD countries and 6 non-OECD economies (Brazil; Chinese Taipei; Hong Kong, China; Israel; Singapore and Sri Lanka). China and India are not included in these estimates and were added to the figures below based on estimates by Oxford Economic Forecasting. The resulting comparison of hourly labour costs is shown in Figure 25.

Figure 25 shows a wide diversity in labour costs, ranging from just over 0.6 USD per hour in China and 1 USD an hour in India, ${ }^{3}$ to over 30 USD an hour in Norway and Denmark. Major OECD countries such as the United States, Japan, Canada, France and the United Kingdom all have hourly labour costs around 20 USD an hour. Germany had the highest level of hourly labour costs among major OECD countries, with 30 USD an hour. Since the estimates are converted by exchange rates to a common currency, exchange rates have a considerable influence on these estimates. For example, hourly labour costs in the Euro-area have risen considerably relative to the United States as the Euro has appreciated. The low position of China in Figure 25 is also influenced by the relatively low value of the Chinese Yuan.

Figure 25. Hourly labour costs in manufacturing, 2003, in USD

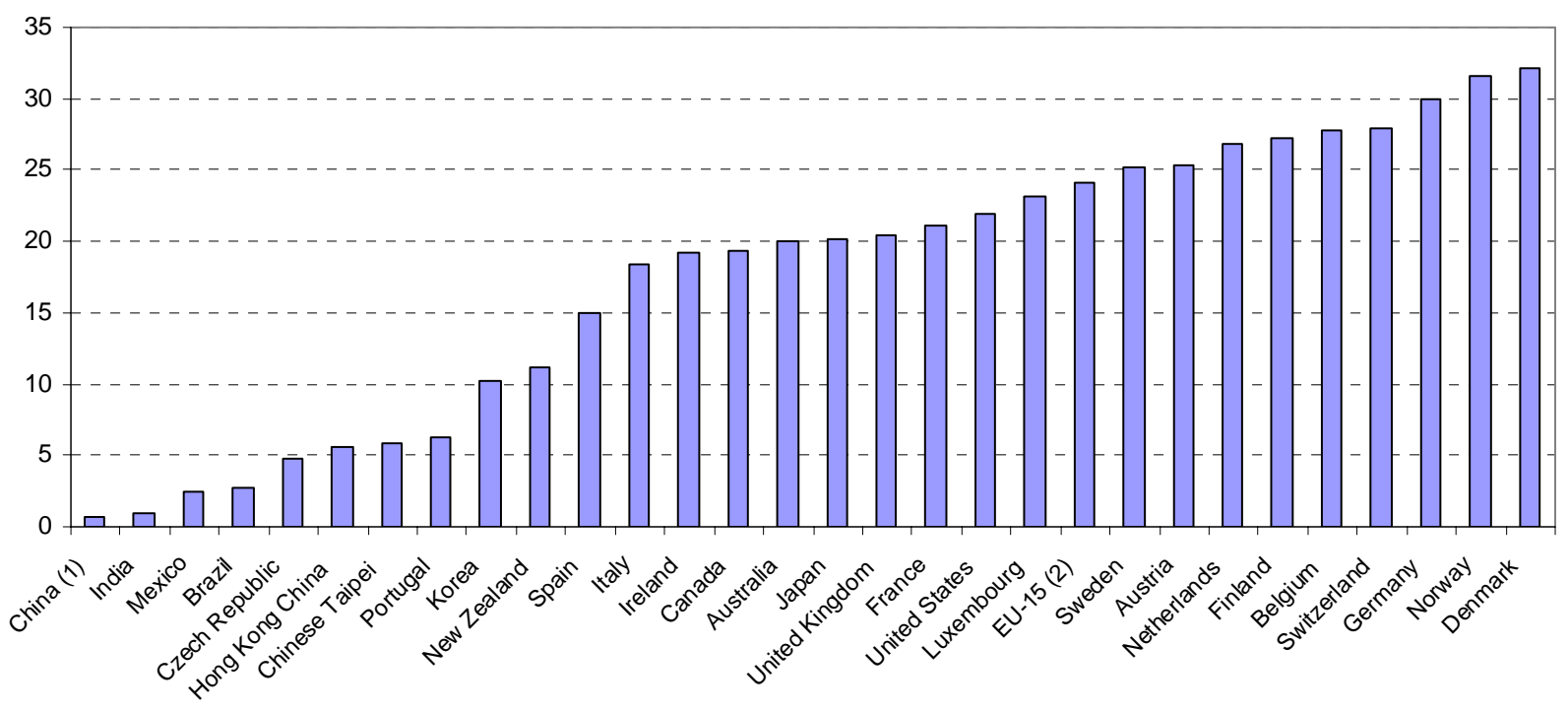

Note: (1) Estimates of Chinese labour compensation may be underestimated as many Chinese workers may benefit from various types of non-monetary compensation, including subsidised accommodation.

(2) Trade-weighted estimates, as shown in BLS (2004).

Source: $\quad$ Estimates from BLS (2004); China and India from Oxford Economic Forecasting.

3. The estimates for China are confirmed by a recent BLS study on manufacturing compensation in China, that finds hourly compensation of about 0.57 USD in 2002 (Banister, 2005b). 
Labour costs should be examined relative to a country's level of productivity in the manufacturing sector. High labour costs can only be supported if they coincide with a high level of labour productivity; conversely, countries with low levels of labour costs typically have low levels of labour productivity. The combination of the estimates of productivity levels presented in Figure 24 and the estimates of labour costs presented in Figure 25 suggest that China has a relatively low level of unit labour costs. However, the figures shown in Figures 24 and 25 are averages; more detailed estimates are required to compare unit labour costs in individual industries. For example, labour costs in high-technology industries may be relatively high in low-income economies if these industries require highly skilled workers that might be more scarce.

\section{The manufacturing sector still accounts for the bulk of spending on research and development}

Of great importance to the role of the manufacturing sector in overall economic activity is its role as a driver of innovation and technological change. While manufacturing's share in employment and value added has declined, the manufacturing sector still accounts for the bulk of business expenditure on R\&D (Figure 26). Its share has declined, however, due to a variety of factors, such as growing R\&D in certain services sectors, the outsourcing of $R \& D$ to specialised $R \& D$ labs that are classified in the services sector, as well as better measurement of R\&D in services.

Figure 26. Share of manufacturing in total business R\&D, 1995 and $2003^{*}$, in \%

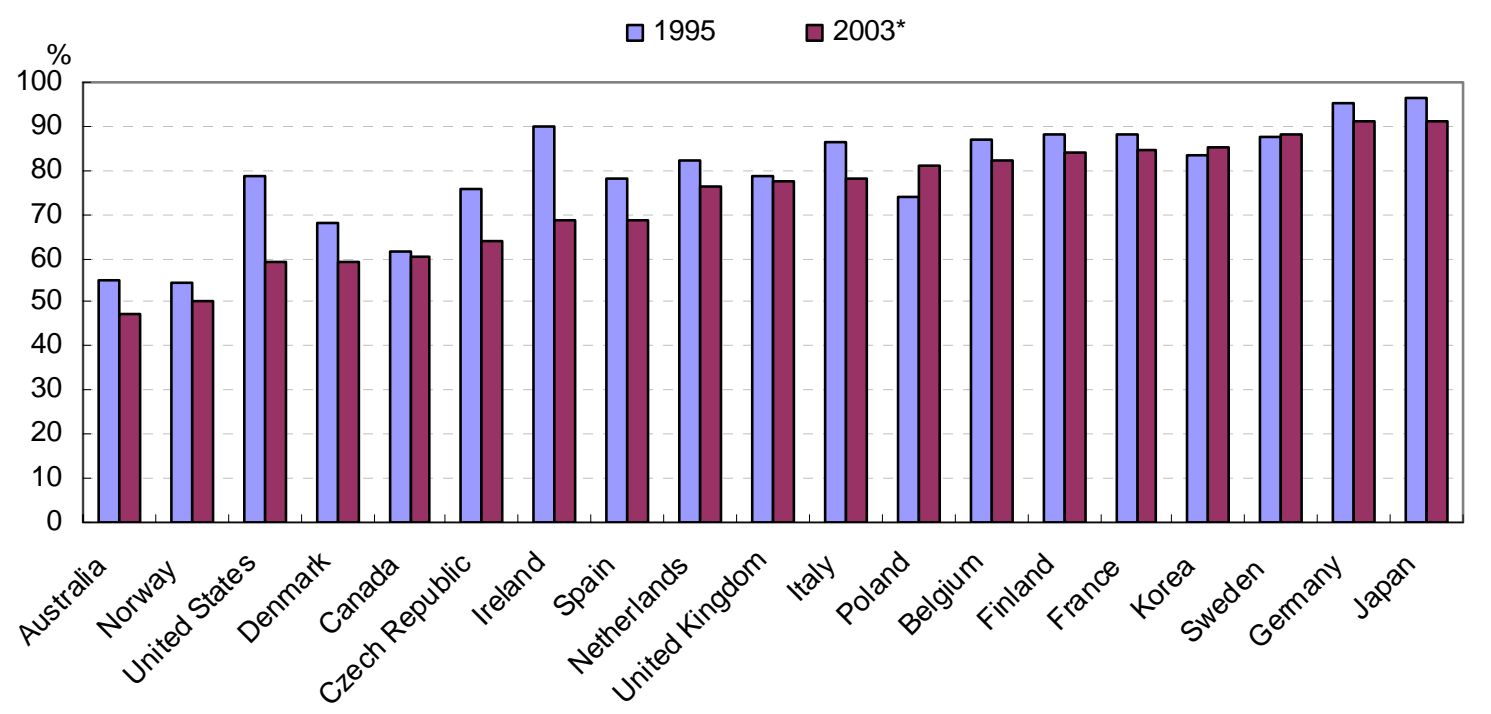

Note: * Or latest available year.

Sources: OECD, ANBERD and STAN Indicators databases, December 2005.

With the end of the "new economy" bubble in 2000, R\&D in manufacturing has declined in many high-technology sectors, as the markets for these industries retracted and profits diminished.

In several OECD countries, manufacturing R\&D is highly concentrated in a few industries and firms. For example, in Canada, Finland, Ireland, the United States and the United Kingdom, over 60\% of all manufacturing R\&D is accounted for by high-technology industries. In other countries, such as Germany, Japan and the Czech Republic, medium-high technology industries account for a large share of the total. Combined, these two technology groups account for $80 \%-90 \%$ of total manufacturing R\&D in most OECD countries, with the exceptions of Australia and Norway (Figure 27). 
Figure 27. Share of technology industries R\&D in \% of total manufacturing R\&D, 2003 *
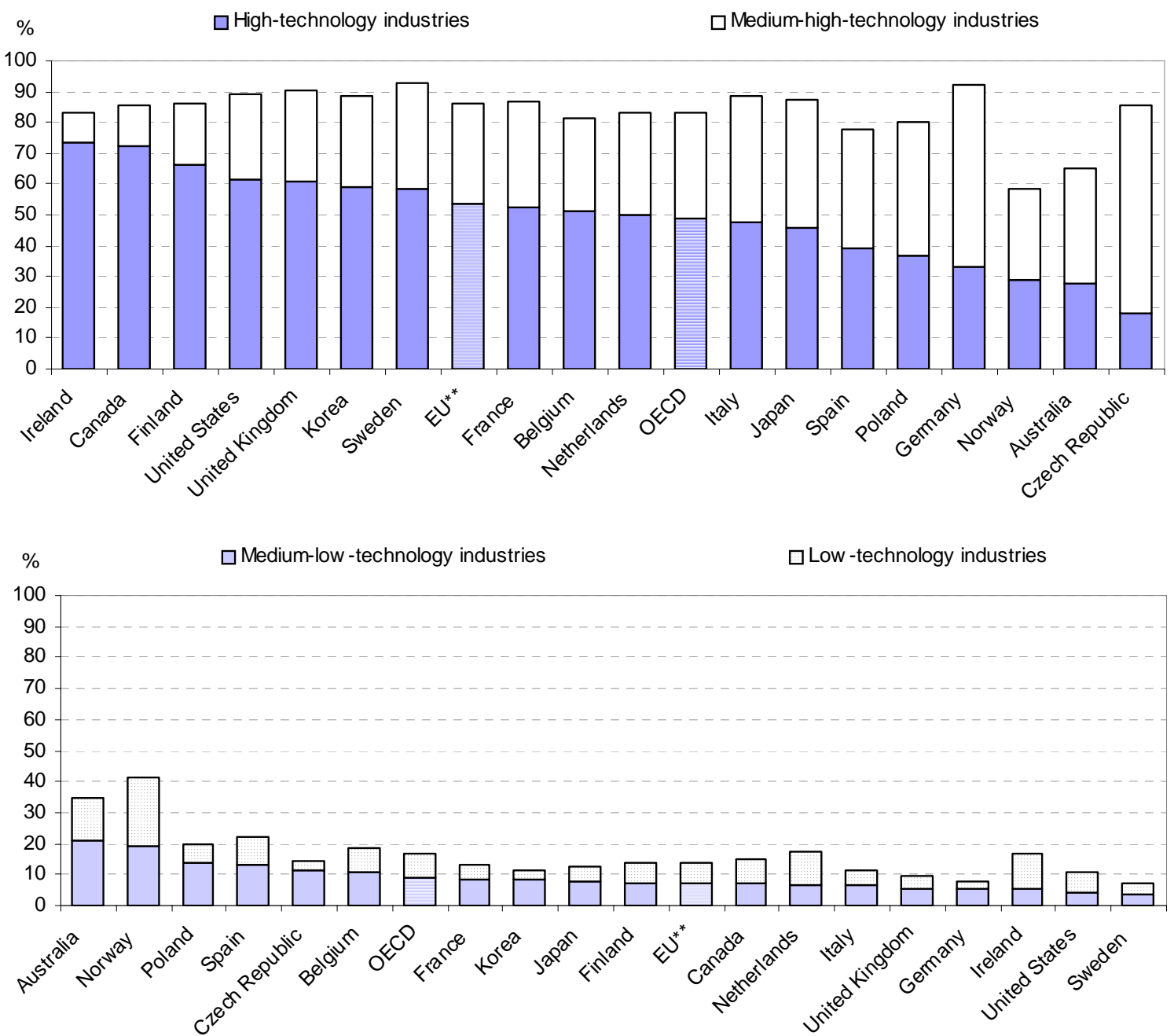

1995

2003 *

$\square$ High-tech

$\square$ Medium-low -tech

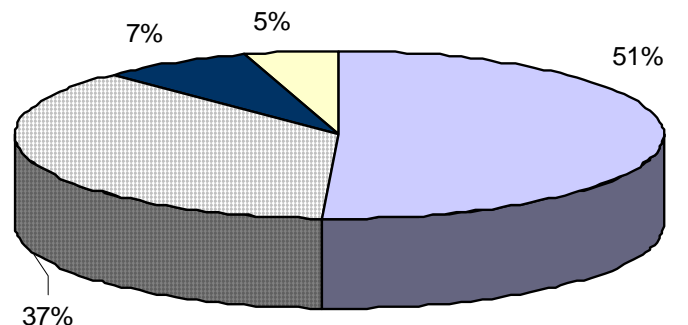

$\square$ Medium-high-tech

$\square$ Low -tech $\square$ High-tech

$\square$ Medium-low -tech $\square$ Medium-high-tech

$\square$ Low -tech

Note: *) Or latest available year. ${ }^{*}$ ) Excluding the Czech Republic and Poland.

Source : OECD, ANBERD and STAN Indicators databases, December 2005. 


\section{DSTI/DOC(2006)9}

\section{OECD countries continue to dominate global innovation}

The R\&D undertaken by manufacturing firms can be turned into patentable innovations. OECD indicators of triadic patents capture major innovations, as they only count those patents that have been filed at all the three major patent offices, the US Patent and Trademark Office, the Japan Patent Office and the European Patent Office. Figure 28 shows the position of different OECD and non-OECD countries on this indicator. It shows that some countries, such as China, Korea and the Russian Federation, have considerable spending on $R \& D$, but so far make a relatively small contribution to triadic patents. These countries are still primarily oriented towards imitation. Others, such as Japan, Germany, Switzerland, Sweden and the Netherlands make a relatively larger contribution to triadic patents than to R\&D. These countries are primarily oriented towards innovation.

Figure 28. Triadic patent families ${ }^{1}$ and industry-financed $R \& D^{2}, 1996-2002$

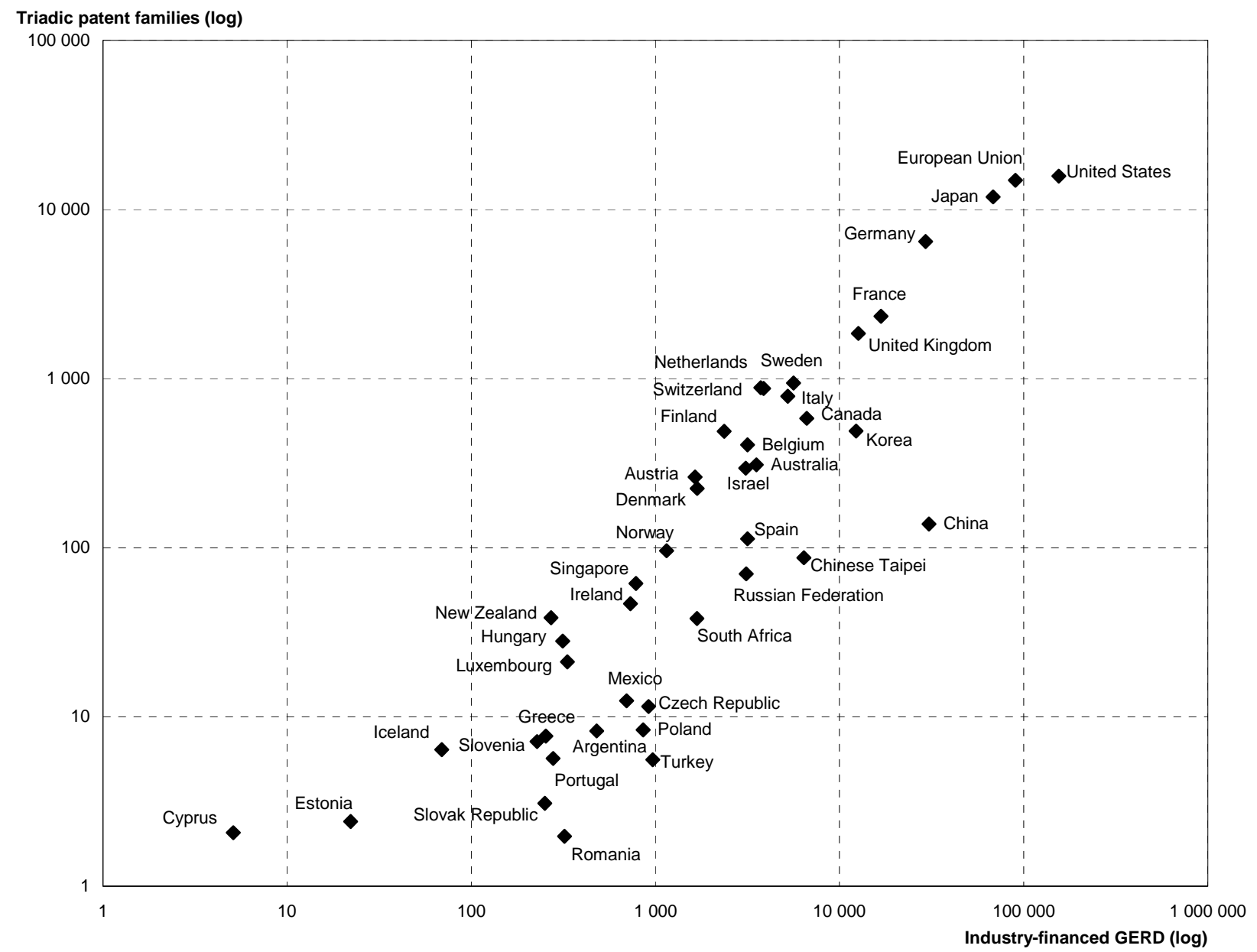

Note: Patent counts are based on the inventor's country of residence, the earliest priority date and fractional counts.

1. Patents all applied for at the EPO, USPTO and JPO. Figures for 2000 to 2002 are estimates.

2. Gross domestic expenditure on R\&D financed by industry, million 2000 USD using purchasing power parities, lagged by one year.

Source: OECD, Patent and R\&D databases, December 2005.

\section{The character of work in the manufacturing sector is changing}

The character of work in the manufacturing sector has changed too, as employment has declined and the manufacturing sector has become more productive and moved up the value chain in many OECD countries. The clearest indication for this change is the growing share of workers in the manufacturing 
sector engaged in services-related occupations. In some OECD countries, such as the Netherlands, more than $50 \%$ of workers in the manufacturing sector were already engaged in a services-related occupation in 2002. Figure 29 shows that in 2002 on average about $40 \%$ of all persons employed in the manufacturing sector were employed in occupations that can be considered as services related, e.g. scientific professionals, accountants, lawyers, managers, clerks or other services occupations. Only about $60 \%$ of all manufacturing workers can still be considered as "production" workers. The share of service-related occupations is particularly high in the Netherlands and the United Kingdom. It remains relatively low in Portugal and Greece.

\section{Figure 29. Share of production and services workers in the manufacturing sector} In percent of total employment of manufacturing, 2002

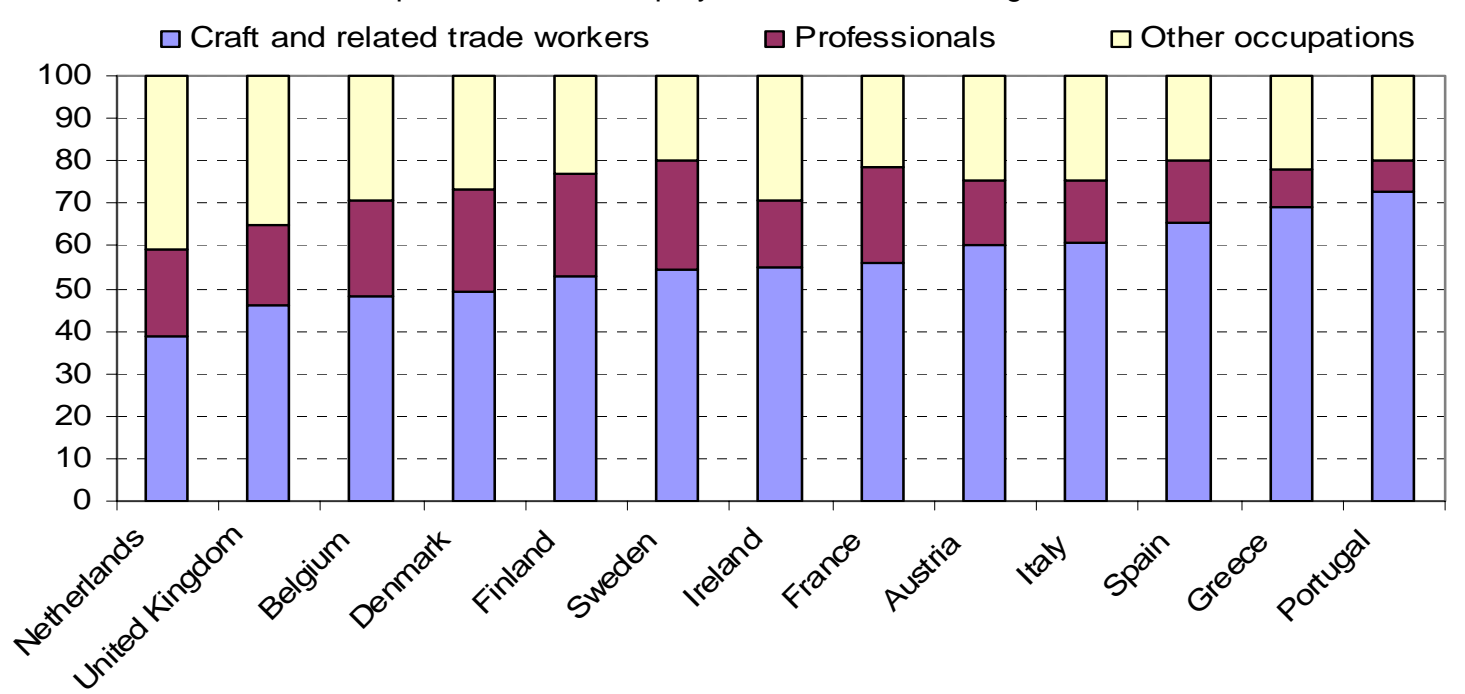

Source : EULFS, 2002.

Figure 30. Share of employment in service-related occupations in the manufacturing sector In percent of total employment of manufacturing, 1995 and 2002

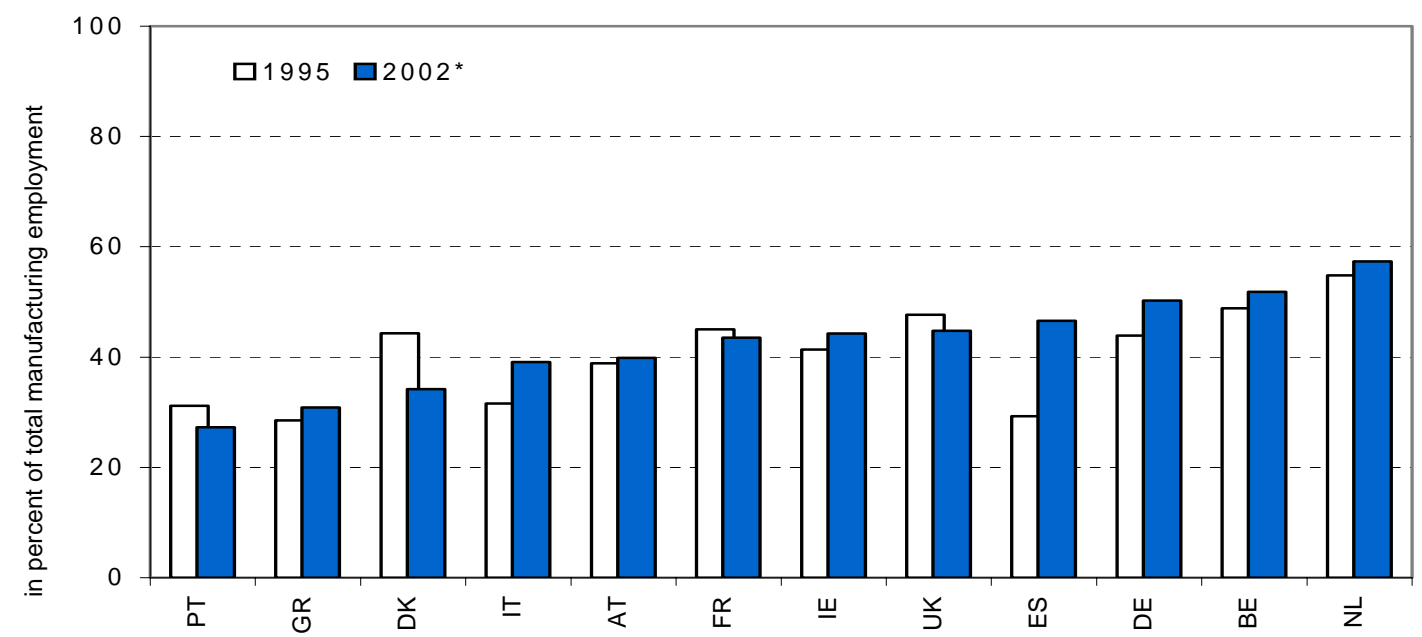

Note: Services-related occupations cover ISCO classes 100-500, 830, 910, 933. These occupations are: legislators, senior officials and managers, professionals and associate professionals, clerks, service workers and shop and market sales workers, as well as drivers, sales and services elementary occupations and transport workers.

*) Data for Germany are from 2001.

Source: EULFS, 1995, 2002. 


\section{DSTI/DOC(2006)9}

The share of service-related occupations in the manufacturing sector has declined since 1995 in the United Kingdom, Denmark and France; it has increased in the other European countries, notably Spain, Italy and Germany (Pilat and Wölfl, 2005; Figure 30). The trend towards a growing share of services workers is consistent with evidence over a longer period. A recent study for the United States, for example, finds a consistent move from labourers to services workers over the $20^{\text {th }}$ century (Wyatt and Hecker, 2006).

A second way to examine the role of workers in the manufacturing sector is to look at the development of their relative wages, e.g. as compared to the economy as a whole, or the business sector. These trends are shown in Figure 31 and suggest that average compensation in the manufacturing sector has not fallen behind that of the economy as a whole and has grown somewhat in several countries. Manufacturing workers have therefore not become less well off compared to other workers. These trends are influenced by several factors, including: $a$ ) more rapid productivity growth in the manufacturing sector than in services in most OECD countries, which is likely to contribute to more rapid wage growth; b) changes in the composition of manufacturing work, as discussed above, with possible impacts on the average wage as the share of some highly paid services workers increases $\left.{ }^{4} ; c\right)$ changes in the structure of the manufacturing sector, with certain low-technology industries and low-wage industries such as textiles and wood products declining in importance, and other industries such as ICT manufacturing and machinery and equipment remaining important.

Figure 31. Labour compensation per employee relative to the total economy, manufacturing Total economy $=100,1980-2003$

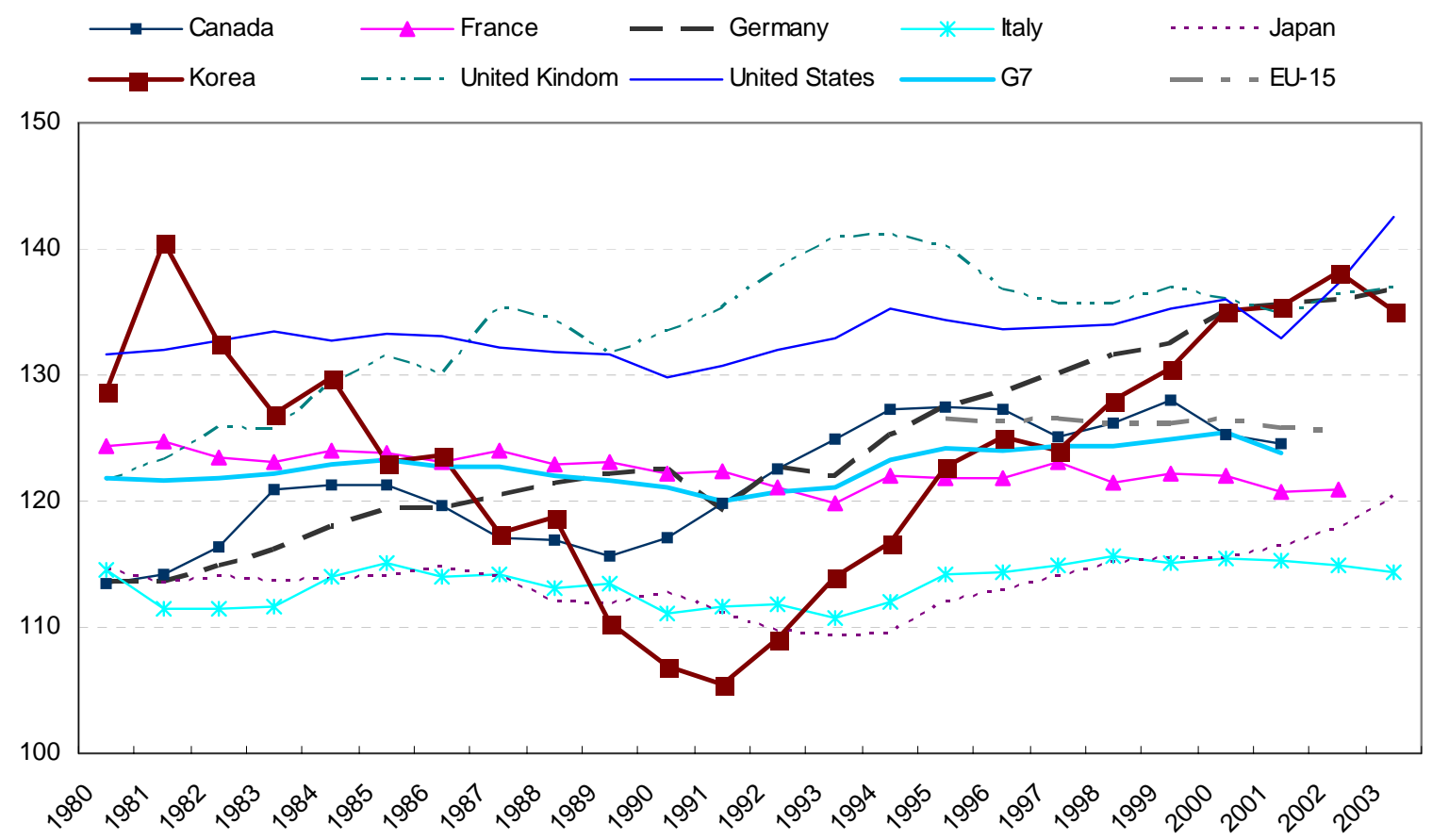

Source : OECD, STAN Indicators database, February 2006.

A third way to examine the role of labour in the manufacturing sector is to look at the labour share in value added. A first glance at these data points to considerable fluctuations in the share of labour in value added, but no clear trend for OECD countries as a whole (Figure 32). As with the previous chart, several factors are likely to be at work here and no simple conclusion can be reached without further analysis.

4. Although services workers may also be less well paid than manufacturing production workers, depending on their occupation. 
Likely factors that play a role are: $a$ ) the occupational shift discussed above, with possibly a higher share of high-skilled workers employed in the manufacturing sector, thus contributing to higher labour shares; b) structural shifts, as discussed above, that may contribute to a higher share of high-skilled workers and thus higher labour shares, but that may also contribute to higher capital shares if the structural shift is towards more capital-intensive industries; $c$ ) changes in the relative bargaining power of manufacturing workers. More detailed analysis, as conducted in other OECD work (De Serres, et al., 2002) would be required to disentangle these, and other factors.

Figure 32. Share of labour compensation in value added in the manufacturing sector In percentage, 1980-2003

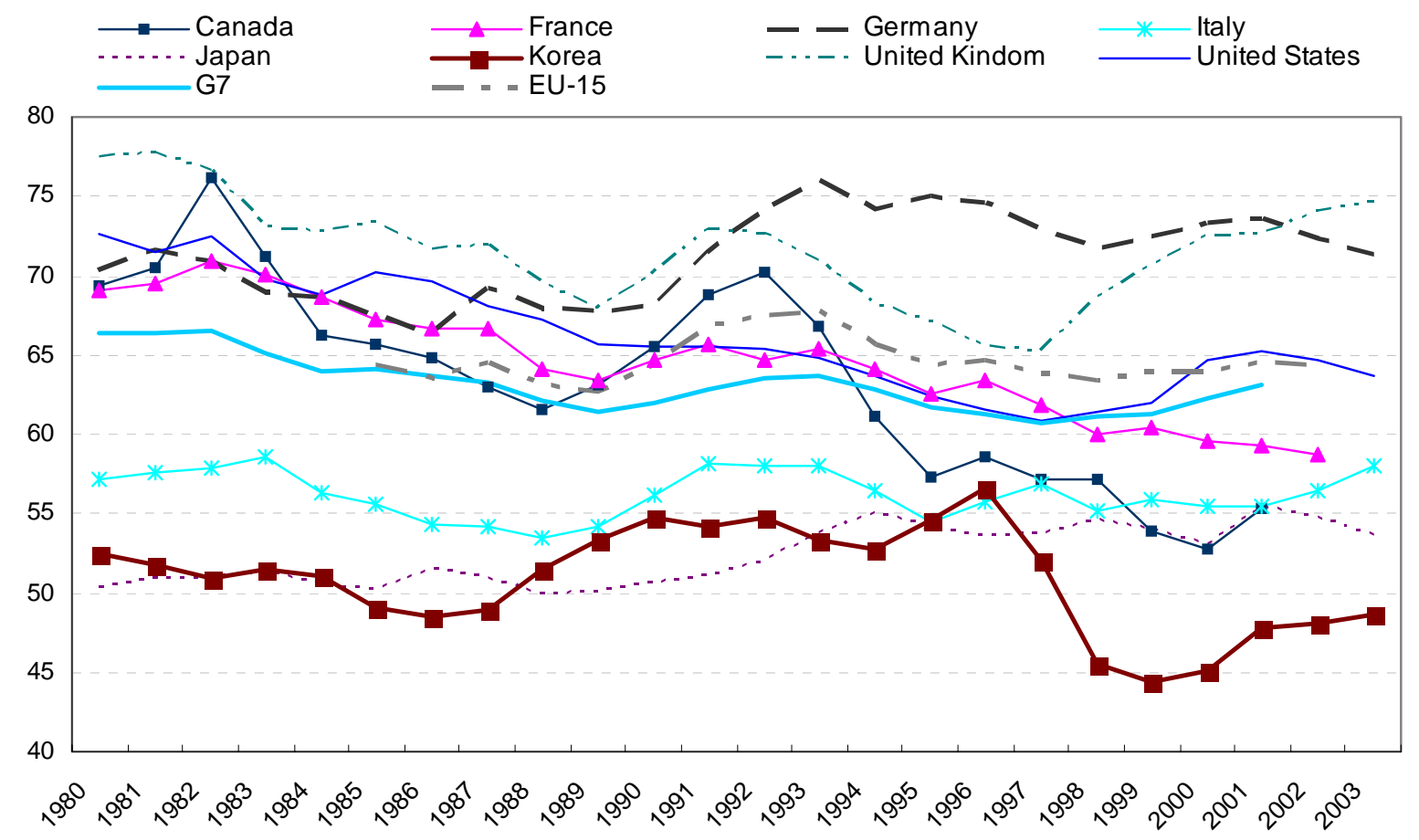

Note: Labour shares are not adjusted for the labour income associated with self-employed workers.

Source : OECD, STAN Indicators database, February 2006.

\section{The distinction between services and manufacturing is blurring}

The interaction between manufacturing and services is increasingly complex and comprises several forms of interaction, including outsourcing of services activities from manufacturing firms to services firms as well as the use of intermediate inputs from an independent service provider that has not been previously integrated in the final good producing firm or industry. The evidence presented in a recent OECD paper (Pilat and Wölfl, 2005) demonstrates that the distinction between manufacturing and services is blurring. Moreover, interactions between services and manufacturing now take on many forms. The main results from the cross-country analysis can be summarised as follows:

1. Input-Output Tables demonstrate that services make important contributions to production, both through their direct contribution to total output and final demand, as well as through their indirect contribution through deliveries of intermediate inputs. The amount of services sector value added that is embodied in manufacturing goods has slowly risen over time and amounted to up to $25 \%-30 \%$ of total output in some countries in the mid-1990s. 
2. Despite anecdotal evidence on a growing share of services turnover within the manufacturing sector, firm-level evidence suggests that manufacturing enterprises in most countries are not very diversified, i.e. they do not have many separate establishments that are engaged in services production. Canada is a notable exception in this respect. In other countries, the diversification of manufacturing firms may primarily occur at the level of the enterprise group, i.e. enterprises in an enterprise group may be engaged in different activities.

3. At the same time, data on turnover by product suggest that manufacturing firms and establishments do derive a greater share of turnover from services activities, notably in countries such as Finland and Sweden. Most of these sales refer to wholesale and retail trade activities carried out by manufacturing firms.

In addition to these three points, the growing role of services occupations in the manufacturing sector also points to the blurring of services and manufacturing. The work also suggests that while the distinction between manufacturing and services is becoming increasingly blurred, the two sectors still differ in their role in the economy. The services sector is more independent from other industries than the manufacturing sector. Most inputs that are necessary to produce demand for services derive from the services sector itself. Manufacturing industries interact much more strongly with other industries, both as providers and as users of intermediate inputs. Even though services now contribute as providers of intermediate input to the performance of other industries, their role remains more limited than that of the manufacturing sector. The evidence presented in the paper also shows that both services and manufacturing are changing; the manufacturing sector is taking on characteristics of the services sector, with a growing share of services occupations and more revenues being derived from services, whereas services are becoming more like manufacturing as they have growing impacts on other sectors of the economy.

\section{Concluding remarks}

So what is happening to manufacturing in OECD countries and what does this imply for the future? These are the questions that can be raised after the brief review of empirical evidence in the previous sections. A few findings should be highlighted:

- The share of the manufacturing sector in total economic activity continues to decline in OECD countries and is likely to do so in the future. The relative decline in the share of manufacturing in production and value added results primarily from relatively slow growth in demand for manufacturing products, as demand for services is growing more rapidly. The relative and absolute decline in manufacturing employment is primarily due to strong productivity growth, but is also affected by the growth of manufacturing capacity in non-OECD countries. At the same time, the loss of manufacturing employment in OECD countries can not simply be characterised as a transfer of manufacturing production to non-OECD countries, as manufacturing employment in non-OECD countries has not grown significantly. Work is currently underway at the OECD to estimate the employment effects associated with off-shoring.

- The character of manufacturing production in OECD countries is changing. The distinction between high-technology and low-technology sectors is becoming less relevant, as certain components of high-technology production can also be carried out in non-OECD countries. Manufacturing activity in OECD countries increasingly incorporates high-value added services. This change seems due to business models that increasingly emphasise intellectual assets and high-value added activities (OECD, 2006), such as research and development, financial and aftersales services, instead of manufacturing production as such. The distinction between manufacturing and services is blurring, complicating empirical analysis with data by economic activity. 
- Manufacturing production has become more and more integrated at the global level. Manufacturing companies increasingly explore which part of production can be carried out at arms length, either within their own country or abroad, or by their foreign affiliates. This leads to a growing fragmentation of production, notably in those industries where production can be fragmented (e.g. electronics) and to growing inter-industry and inter-firm trade. Due to these changes, trade patterns and patterns of comparative advantage across countries are increasingly complex as they are heavily influenced by location choices of multinational enterprises.

- Innovation in manufacturing remains dominated by OECD countries. The emphasis on high value added activities translates in a growing importance of innovation. Research and development in non-OECD countries is growing, notably in China. Thus far, growth of R\&D in non-OECD countries has not translated into much new innovation, as measured by triadic patents. OECD countries continue to account for the bulk of global patenting activity. That being said, the R\&D intensity of OECD countries has not grown significantly in recent years, even if there appears to be a growing emphasis on innovation in national policies. ${ }^{5}$

These trends raise two major challenges for OECD countries. The first challenge concerns the structural shift from manufacturing to services and the implications this has for the labour market in OECD countries. Governments will need to facilitate this shift and help displaced workers find alternative employment. Two recent OECD reports (OECD, 2005a, 2005d) have set out a range of policies that can support such structural change, including policies to improve the functioning of labour and products markets, to open markets to international trade and investment, to strengthen education and training, to enhance innovation and technology policies, as well as tax policies.

The second challenge is how to ensure the continued presence of a viable manufacturing sector in OECD countries. Maintaining such a presence may be particularly important if manufacturing activity remains the main source of technological progress. Several policies could be considered in this context and will be discussed in more detail in further work in the context of this project.

5. Available measures of R\&D intensity do not account for the possibility that the productivity of R\&D could have increased, implying that less $\mathrm{R} \& \mathrm{D}$ expenditure might be required to lead to growing output. Improved measurement of R\&D in real terms will be required to investigate this issue. 


\section{ANNEX: SOURCES}

STAN - Industry: The STAN database for Industrial Analysis includes annual measures of output, labour input, investment and international trade by economic activity which allow users to construct a wide range of indicators focused on areas such as productivity growth, competitiveness and general structural change. The industry list based on the International Standard Industrial Classification (ISIC) Rev. 3, provides sufficient details to enable users to highlight high-technology sectors and is compatible with those lists used in related OECD databases in the 'STAN' family (see below). STAN-Industry is primarily based on member countries' annual National Accounts by activity tables and uses data from other sources, such as national industrial surveys/censuses, to estimate any missing detail. Since many of the data points in STAN are estimated, they do not represent the official member country submissions. See: www.oecd.org/sti/stan

Publication: STAN-industry is available on line via SourceOECD ( www.sourceoecd.org ) where it is regularly updated (new tables are posted as soon as they are ready). A "snapshot" of STAN-industry is also available on CDROM together with the latest versions of STAN - R\&D (ANBERD), STAN Bilateral Trade and a set of derived STAN Indicators. See www.oecd.org/sti/stan/indicators.

STAN - R\&D (ANBERD): The Analytical Business Enterprise Research and Development database is an estimated database constructed with a view to creating a consistent data set that overcomes the problems of international comparability and time discontinuity associated with the official business enterprise R\&D data provided to the OECD by its member countries. ANBERD contains R\&D expenditures for the period 1987-2003, by industry (ISIC Rev. 3), for 19 OECD countries. See: www.oecd.org/sti/anberd.

Publication: OECD (2004), Research and Development Expenditure in Industry 2004. Annual. ANBERD is also available on line via SourceOECD (under the STAN heading) as well as on the STAN family CDROM.

STAN - Bilateral Trade (BTD): This database presents detailed trade flows by manufacturing industry between a set of OECD declaring countries and a selection of partner countries and geographical regions. Data are presented in thousands of USD at current prices and have been derived from the OECD database International Trade by Commodities Statistics (ITCS - formerly Foreign Trade Statistics or FTS). Imports and exports are grouped according to the country of origin and the country of destination of the goods. The data have been converted from product classification schemes to an activity classification scheme based on ISIC Rev.3, compatible with those of the OECD's STAN-Industry, Input-Output Tables and ANBERD databases. See: www.oecd.org/sti/btd.

Publication: OECD, Bilateral Trade Database. BTD is available on line via SourceOECD (under the STAN heading) as well as on the STAN family CDROM.

STAN - I-O: The set of OECD Input-Output Tables used in this paper consists of matrices of interindustrial transaction flows of goods and services (domestically produced and imported) in current prices for 18 OECD countries and two non-member OECD economies (Brazil and China) covering one or more years around the mid-1990s. The tables are based on ISIC Rev. 3 and are available for free in zipped Excel format. See: www.oecd.org/std/io-tables/data. A new set of IO tables, covering a year around 2000, is 
currently being prepared by OECD and will be released by the end of 2006, or early 2007. See Yamano and Ahmad (2006).

R\&D: The $\mathbf{R} \& \mathbf{D}$ database contains the full results of the OECD surveys on $\mathbf{R} \& \mathbf{D}$ expenditure and personnel. This database serves, inter alia, as raw material for both the ANBERD and MSTI databases.

Publication: OECD (2005), Research and Development Statistics: 2004 Edition (formerly Basic Science and Technology Statistics) Updated annually on CD-ROM as OECD Science and Technology Statistics (a printed edition is also available every two years).

MSTI: The Main Science and Technology Indicators database provides a selection of the most frequently used annual data on the scientific and technological performance of OECD member countries and nine non-member economies (Argentina, China, Israel, Romania, Russian Federation, Singapore, Slovenia, South Africa, Chinese Taipei). The indicators, expressed in the form of ratios, percentages, growth rates, cover resources devoted to $\mathrm{R} \& \mathrm{D}$, patent families, technology balance of payments and international trade in highly R\&D-intensive industries.

Publication: OECD (2005), Main Science and Technology Indicators 2005/2. Biannual. Also available on CD-ROM as OECD Science and Technology Statistics.

Patent database: This database contains patents filed at the largest national patent offices - European Patent Office (EPO); US Patent and Trademark Office (USPTO); Japanese Patent Office (JPO) - and other national or regional offices. Each patent is referenced by: patent numbers and dates (publication, application and priority); names and countries of residence of the applicants and of the inventors; and technological categories, using the national patent classification as well as the International Patent Classification (IPC). The compiled indicators mainly refer to single patent counts in a selected patent office, as well as counts of triadic patent families (patents filed at the EPO, the USPTO and the JPO to protect a single invention). See: www.oecd.org/sti/ipr-statistics

The series are published on a regular basis in OECD, Main Science and Technology Indicators.

AFA: The Activities of Foreign Affiliates database presents detailed data on the performance of foreign affiliates in the manufacturing industry of OECD countries (inward and outward investment). The data indicate the increasing importance of foreign affiliates in the economies of host countries, particularly in production, employment, value added, research and development, exports, wages and salaries. AFA contains 18 variables broken down by country of origin and by industrial sector (based on ISIC Rev. 3) for 23 OECD countries.

Publication: OECD, Measuring Globalisation: Economic Globalisation Indicators. 2005. Also available annually on line on SourceOECD (www.sourceoecd.org).

FATS: This database gives detailed data on the activities of foreign affiliates in the services sector of OECD countries (inward and outward investment). The data indicate the increasing importance of foreign affiliates in the economies of host countries and of affiliates of national firms implanted abroad. FATS contains five variables (production, employment, value added, imports and exports) broken down by country of origin (inward investments) or implantation (outward investments) and by industrial sector (based on ISIC Rev. 3) for 21 OECD countries.

Publication: OECD, Measuring Globalisation: Economic Globalisation Indicators. 2005. 
DSTI/DOC(2006)9

\section{Other OECD databases:}

ITCS: International Trade by Commodity Statistics (Statistics Directorate).

Productivity (Statistics Directorate, Directorate for Employment, Labour and Social Affairs, Directorate for Science, Technology and Industry).

Further details on OECD statistics are available at: $\underline{\text { www.oecd.org/statistics/ }}$ 
DSTI/DOC(2006)9

\section{REFERENCES}

Banister, J. (2005a), “Manufacturing Employment in China”, Monthly Labor Review, July 2005, pp. 11-29, Bureau of Labor Statistics, Washington, D.C.

Banister, J. (2005b), "Manufacturing Earnings and Compensation in China”, Monthly Labor Review, August 2005, pp. 22-40, Bureau of Labor Statistics, Washington, D.C.

Bureau Fédéral du Plan (2004), L’industrie a-t-elle un avenir en Belgique?, Working Paper 10-04, Brussels.

Conference Board (2004a), "Can Manufacturing Survive in Advanced Countries”, Executive Action, No. 93, March, New York.

Conference Board (2004b), “China's Experience with Productivity and Jobs", Research Report $R-1352-04-R R$, New York.

De Serres, A., S. Scarpetta and C. de la Maisonneuve (2002), "Sectoral shifts in Europe and the United States: How they affect aggregate labour shares and the properties of wage equations", Economics Department Working Papers No. 326, OECD, Paris.

Ministry of Economic Affairs (2004), “Toekomstvisie op de industries”, The Hague, November.

OECD (2004), A New World Map in Textiles and Clothing, OECD, Paris.

OECD (2005a), Enhancing Services Sector Performance, Paris.

OECD (2005b), Measuring Globalisation - Economic Globalisation Indicators, Paris.

OECD (2005c), Science, Technology and Industry Scoreboard 2005, Paris.

OECD (2005d), Trade and Structural Adjustment, Paris.

OECD (2006), Creating Value from Intellectual Assets, Paris.

Dirk Pilat and Anita Wölfl (2005), “Measuring the Interaction between Manufacturing and Services”, STI Working Paper 2005/5, OECD, Paris.

Ritter, R.C. and R.A. Sternfels (2004), “When offshore manufacturing doesn’t make sense”, The McKinsey Quarterly, 2004, No. 4, pp. 124-127.

UK Department of Trade and Industry (2004), Review of the Government's Manufacturing Strategy, London.

US Department of Commerce (2004), Manufacturing in America, Washington, D.C. 


\section{DSTI/DOC(2006)9}

Wixted, B., N. Yamano and C. Webb (2006), "Input-Output Analysis in an Increasingly Globalised World: Applications of OECD’s Harmonised International Tables”, STI Working Paper 2006/7, OECD, Paris.

Wölfl, A. (2005), “The Service Economy in OECD Countries”, Enhancing the Performance of the Services Sector, Chapter 2, OECD, Paris.

Wyatt, I.D. and D.E. Hecker (2006), “Occupational changes during the $20^{\text {th }}$ century”, Monthly Labor Review, March, pp. 35-57, Bureau of Labor Statistics, Washington, D.C.

Yamano, N. and N. Ahmad (2006), “The OECD Input-Output Database: 2006 Edition”, STI Working Paper 2006/8, OECD, Paris. 